\title{
Axial Compression Performance and Ultrasonic Testing of Multicavity Concrete-Filled Steel Tube Shear Wall under Axial Load
}

\author{
Hongbo Li $\left(\mathbb{D},{ }^{1,2,3}\right.$ Pengfei Yan $\left(\mathbb{D},{ }^{1} \text { Hao Sun } \mathbb{D}^{1},{ }^{1,4} \text { and Jianguang Yin }{ }^{1}\right)^{1}$ \\ ${ }^{1}$ College of Civil and Hydraulic Engineering, Ningxia University, Yinchuan 750021, China \\ ${ }^{2}$ Ningxia Research Center of Technology on Water-saving Irrigation and Water Resources Regulation, Yinchuan 750021, China \\ ${ }^{3}$ Engineering Research Center for Efficient Utilization of Water Resources in Modern Agriculture in Arid Regions, \\ Yinchuan 750021, China \\ ${ }^{4}$ School of Civil Engineering, Central South University, Changsha 410075, China \\ Correspondence should be addressed to Hao Sun; 12018130640@nxu.edu.cn
}

Received 29 June 2020; Revised 16 October 2020; Accepted 29 October 2020; Published 17 November 2020

Academic Editor: Michael Yam

Copyright (c) 2020 Hongbo Li et al. This is an open access article distributed under the Creative Commons Attribution License, which permits unrestricted use, distribution, and reproduction in any medium, provided the original work is properly cited.

\begin{abstract}
In this study, the mechanical performance of multicavity concrete-filled steel tube (CFST) shear wall under axial compressive loading is investigated through experimental, numerical, and theoretical methodologies. Further, ultrasonic testing is used to assess the accumulated damage in the core concrete. Two specimens are designed for axial compression test to study the effect of concrete strength and steel ratio on the mechanical behavior of multicavity CFST shear wall. Furthermore, a three-dimensional (3D) finite element model is established for parametric studies to probe into compound effect between multicavity steel tube and core concrete. Based on finite element simulation and limit equilibrium theory, a practical formula is proposed for calculating the axial compressive bearing capacity of the multicavity CFST shear wall, and the corresponding calculation results are found to be in good agreement with the experimental results. This indicates that the proposed formula can serve as a useful reference for engineering applications. In addition, the ultrasonic testing results revealed that the damage process of core concrete under axial load can be divided into three stages: extension of initial cracks (elastic stage), compaction due to hooping effect (elastic-plastic stage), and overall failure of the concrete (failure stage).
\end{abstract}

\section{Introduction}

With the rapid development of high-rise buildings, steelconcrete composite structures have emerged as a new composite structure in the construction industry. Such structures are generally used to assemble beams, plates, columns, walls, etc. The steel-concrete composite structure can fully utilize the mechanical properties of steel tube and self-compacting concrete. The confining effect of steel tube on the core concrete places the concrete in a three-dimensional (3D) stress state, which significantly improves the strength, toughness, and plastic properties of the concrete. Further, since the concrete is filled inside the steel tube, it is possible to delay or prevent premature local buckling of the outer steel tube. Steel tube and concrete not only compensate each other's shortcomings but also give full play to each other's advantages. Consequently, this composite structure exhibits high bearing capacity, good plasticity, and convenient construction properties [1-7].

Over the past few decades, several studies have focused on single-cavity concrete-filled steel tube (CFST) shear wall. For example, Liu and Young [8] studied the overall geometric defects and material properties of square CFST under axial compression. Chang et al. [9] and Starnes et al. [10] examined the performance of round steel tubes with defects under axial compression load. Chen [11] and Liu et al. [12] suggested that CFST with a circular cross section has a strong ferrule effect, and its bearing capacity is high under axial pressure. The ferrule effect can be fully reflected when it is used for axial compression members or small biased 
members. Fang conducted a series of experimental studies on the mechanical properties of CFST, including axial compression [13, 14], bending [15], axial tension [16], partial tension (tensile shear) [17], and seismic performance [18]. The results showed that the reinforcement of high-strength concrete shear wall steel tube effectively improved the brittleness of high-strength concrete. Such shear wall exhibited higher axial compression capacity than the ordinary shear wall and still had higher residual bearing capacity after the concrete column outside the tube was destroyed. Under the effect of monotonic horizontal load, the lateral stiffness and bending bearing capacity were improved, and the stiffness and bearing capacity were gradually degraded. The pseudo-static (low-cycle reciprocating horizontal loading) test showed that the shear wall retained good ductility at a high axial compression ratio (0.7). In addition, Hossain et al. [19, 20] and Rafiei et al. [21, 22] experimentally examined the performance of steel plate-concrete composite shear wall with a pair of tensile connectors under the action of reciprocating hysteresis and unidirectional push-over loads. The results showed that the presence of tensile connectors further improved the ductility and energy consumption capacity of the component and prevented premature buckling of the profiled steel plate. However, the final failure mode of the specimen was still partially straightened under the action of diagonal tension band, resulting in a loss of bearing capacity of the specimen. Zhang et al. [23] examined the cracking mechanism of slab-concrete composite shear wall and its control measures. The results showed that the steel plate of the shear wall structure pre-expanded in the steel plate before the concrete finally solidified. The shrinkage of the steel plate gradually prevented harmful cracks. Ma et al. [24] proposed a formula for calculating the effective stiffness of a steel plate-concrete composite shear wall during normal use. Gan et al. [25] and Zhang et al. [26] studied the seismic performance of 16 sheet-concrete composite shear walls with different heightwidth ratios, axial compression ratios, steel ratio of steel plates, and structural measures. The results showed that the studs welded on steel plates effectively strengthened the bonding performance between steel plates and concrete and were conducive to improving the deformation capacity, ductility, and energy consumption of components. Li et al. [27] investigated the axial compressive properties of short, square CFST columns with different cavity numbers and varying ratios of inner and outer wall thickness. The results showed that the inner cavity plate improved the deformation performance of the specimen, and the specimen with an inner and outer wall thickness ratio of 1.5 was better than those with a thickness ratio of 1 and 2.5. Wang et al. [28] studied the influence of axial compression ratio, concrete strength, and steel plate thickness on the bending performance of multicavity CFST shear wall through experiments and finite element simulation. The results showed that the steel plate thickness had the strongest effect on the bending performance of shear wall. Wang et al. [29] studied the axial compression performance of L-shaped and T-shaped CFST columns through experiments and finite element simulation. A finite element analysis (FEA) model was established to investigate the effects of steel tube thickness, concrete strength, steel yield strength, and slenderness ratio. In addition, a formula was established to calculate the axial compression strength and stable bearing capacity of L/TCFST column, which could provide a reference for practical engineering applications. Liu et al. [30] studied the static performance of notched hexagonal CFST columns under axial loading. The results showed that the notch in the steel tube weakened the inhibitory effect of steel tube on the core concrete, resulting in a decrease in the ultimate strength of the specimens. Yin et al. [31, 32] studied the mechanical properties of special-shaped multicavity CFST columns under reciprocating axial load and different loading directions. The results showed that if the interaction between internal diaphragm and concrete was neglected, then the calculated ultimate bearing capacity was less than the test value. Therefore, it is necessary to establish an effective method for calculating the bearing capacity of specialshaped multicavity CFST columns. Chen et al. [33, 34] studied the damage state of CFST and reinforced CFST under axial load through ultrasonic testing. The results showed that the damage state of core concrete of CFST and reinforced CFST under axial load changed in a three-stage and fivestage pattern, respectively. Dong et al. $[35,36]$ studied the cavitation defects of rectangular and circular CFST columns with self-compacting concrete using ultrasonic waves. The results suggested that ultrasonic testing method was useful in detecting the defects of CFST, and a more accurate method to judge the sound velocity of the defects and an effective method to deal with the defects were proposed.

All the above studies indicated that steel-concrete composite structures have good bearing capacity and seismic performance. However, the research on multicavity CFST shear wall is still in its infancy. In particular, the mechanical properties of in-line multicavity steel tube with self-compacting concrete shear wall have been rarely investigated in the existing literature. The multicavity steel tube shear wall and the reinforced concrete shear wall have obvious differences in failure mechanism and mechanical performance. If an actual engineering structure is designed according to reinforced concrete shear wall, the calculated results can be conservative. Although the working mechanisms of steel plate-concrete shear wall and multicavity steel tube shear wall are similar, their construction form and cross-sectional size are different. It is impossible to directly calculate the shear force of multicavity steel tube based on the relevant theory of steel plate-concrete shear wall. Therefore, it is necessary to systematically examine the failure mechanism and mechanical performance of multicavity steel tube with selfcompacting concrete shear wall and establish relevant theoretical model and design methods, which are the objectives of this study. Based on the Shantytown reconstruction project of Hongxinyuan City in Hongguang Town, China, the mechanical performance of multicavity CFST shear wall under axial compressive loading is investigated through experiments, FEA, theoretical analysis, and ultrasonic testing. The results can provide useful guidance for engineering design. 


\section{Experimental Method}

2.1. Material Properties. The multicavity steel tube used in the test had a yield strength of $235 \mathrm{MPa}$ and nominal thickness of $2 \mathrm{~mm}$. According to the provisions of tensile testing of metallic materials, the steel tube was subjected to unidirectional tensile test. The measured mechanical properties of steel are shown in Table 1. The steel tube was filled with C40 self-compacting concrete in which silica fume and fly ash were added. Li et al. [37] and Golewski [38, 39] demonstrated that the addition of fly ash in self-compacting concrete can not only increase its flow performance but also protect the environment and save energy. Based on the material tests, the best mixing proportion of self-compacting concrete was obtained [37]. The strength of concrete prism was $38.17 \mathrm{MPa}$.

2.2. Specimen Design. Two in-line multicavity CFST shear wall specimens were designed to conduct axial compression test. Figure 1 shows a cross-sectional schematic of the shear wall specimens. The design parameters of these specimens are listed in Table 2.

2.3. Loading System. Firstly, the instrument was calibrated. Secondly, during the formal test, according to the "Standard for Test Methods of Concrete Structures (GB/T 50152-2012)," in the elastic phase, $1 / 10$ of the estimated load was applied in each stage. After the steel plate in the compression area reached the yield strain, 1/20 of the expected bearing capacity was taken as the load for each stage, which was retained for $1 \mathrm{~min}$. When the test load reached the peak load, the continuous loading process was slowed down. Finally, when the load dropped below $75 \%$ of the peak load, the shear wall was considered to be broken and loading was stopped. The loading system is shown in Figure 2.

\section{Axial Compression Test and Results}

3.1. Testing of YA4-600. Figure 3 shows the failure diagram of YA4-600 specimen. Until the load is increased to $448.7 \mathrm{kN}$ (70\% of the peak load), there is no significant change in the specimen. When the load is increased to $576.09 \mathrm{kN}$ ( $90 \%$ of the peak load), bulging phenomenon occurs at a height of nearly $50 \mathrm{~mm}$ from the top, but other parts do not show obvious bulging, as shown in Figure 3(a). This is due to the presence of stiffener, which causes stress concentration in the steel plate, and the steel plate buckles before other parts. However, with the increase in load, the buckling deformation does not increase gradually, which indicates that buckling deformation has a minor effect on the overall shear wall. When the load is increased to $641.09 \mathrm{kN}$ (peak load), the center of the web begins to show bulging phenomenon, as shown in Figure 3(b), and as the load continues to increase, the bulging phenomenon becomes more obvious. Subsequently, the load is gradually decreased, while the displacement continues to increase, and eventually the load tends to stabilize. Here, it is considered that the shear wall is broken, and the loading is stopped. Finally, the multicavity steel tube shear wall exhibits multiwave buckling failure. It can be seen from Figure 3(b) that the failure of shear wall specimen is mainly concentrated at $200-300 \mathrm{~mm}$ away from the top, and the multiwave buckling failure of the steel plate is eventually destroyed.

3.2. Testing of YA5-600. Figure 4 shows the failure diagram of YA5-600 specimen. When the load is increased to $553.21 \mathrm{kN}$ (70\% of the peak load), there is no obvious change in the specimen. When the load is increased to $711.26 \mathrm{kN}$ ( $90 \%$ of the peak load), bulging phenomenon occurs near $50 \mathrm{~mm}$ from the top, but there is no obvious bulging in the other parts, as shown in Figure 4(a). This is again due to the presence of stiffener, which causes stress concentration in the steel plate, and the steel plate bends before other parts. However, as the load continues to increase, the buckling deformation does not increase gradually, which indicates that the buckling deformation at this point has a negligible impact on the entire shear wall. When the load is increased to $790.30 \mathrm{kN}$ (peak load), the silver powder outside the steel tube begins to peel off, and bulging phenomenon begins to appear in the middle of the web, as shown in Figure 4(b). As the loading increases, the bulge becomes more obvious. Further, the load is gradually decreased, while the displacement continues to increase, and the load finally tends to be stable. Here, the shear wall is considered to be damaged, and the loading is stopped. Finally, the multicavity steel tube shear wall shows multiwave buckling failure. As shown in Figure 4(b), the failure of shear wall specimen is mainly concentrated at $300 \mathrm{~mm}$ away from the top. The multiwave buckling failure of the steel plate is a bending buckling failure, as shown in Figure 4(c).

3.3. Relationship between Axial Load and Strain. The axial load vs. longitudinal strain curve of multicavity CFST can directly reflect the mechanical behavior of CFST. Strain gauges can be used to measure the local deformation of shear wall specimen with high accuracy, but the measurement range is limited. Although displacement meter has a large measurement range, its measurement accuracy is not good. Therefore, strain gauges can provide a relatively accurate measurement of the deformation of the specimen when it is in the elastic stage at the beginning of loading. As the load continues to increase and the specimen enters the plastic stage, the strain gauge can no longer accurately reflect the longitudinal deformation of the shear wall specimen. The average longitudinal deformation at this stage is obtained by using a displacement meter. Finally, the axial load vs. strain curve of the multicavity CFST shear wall is obtained, which is shown in Figure 5. It is clear that the bearing capacities of inline multicavity CFST shear wall specimens are 641.10 kN (YA4-600) and 790.29 kN (YA5-600).

\section{Establishment and Analysis of the Finite Element Model}

4.1. Establishment of the Finite Element Model. For establishing the model, it is assumed that the steel is isotropic. A five-stage constitutive model for stress-strain relationship 
TABLE 1: Measured properties of steel.

\begin{tabular}{|c|c|c|c|c|c|}
\hline $\begin{array}{l}\text { Measured thickness } t \\
(\mathrm{~mm})\end{array}$ & $\begin{array}{l}\text { Tensile strength } f_{\mathrm{u}} \\
(\mathrm{MPa})\end{array}$ & $\begin{array}{c}\text { Yield strength } f_{\mathrm{y}} \\
(\mathrm{MPa})\end{array}$ & $\begin{array}{c}\text { Elastic modulus } E_{\mathrm{s}} \\
(\mathrm{MPa})\end{array}$ & Poisson's ratio $\mu_{\mathrm{s}}$ & Elongation $\delta_{\mathrm{s}}$ \\
\hline 1.72 & 416.70 & 298.42 & $2.07 \times 10^{5}$ & 0.29 & 0.35 \\
\hline
\end{tabular}

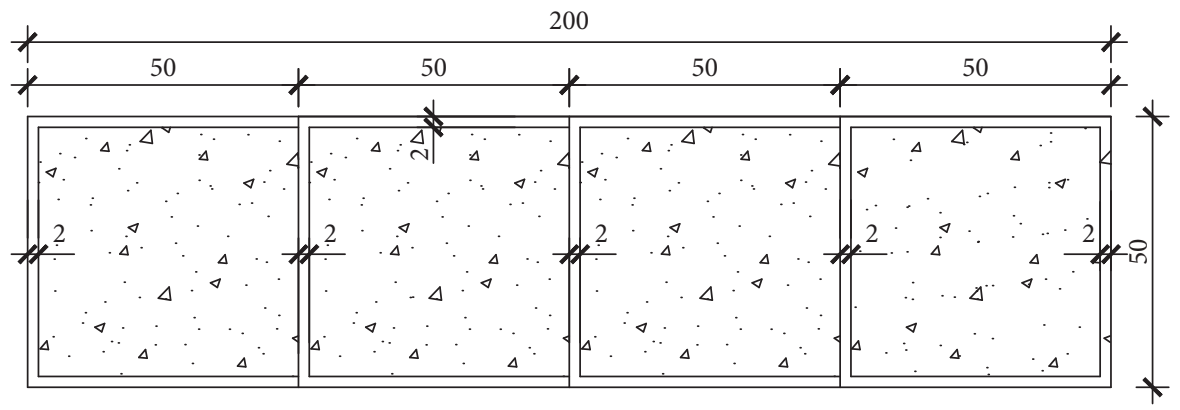

FIgUre 1: Cross-sectional schematic of in-line multicavity CFST shear wall (unit: $\mathrm{mm}$ ).

TABLE 2: Design parameters of shear wall specimens.

\begin{tabular}{|c|c|c|c|c|c|c|}
\hline Number & Specimen number & Cavity thickness $t_{\mathrm{w}}(\mathrm{mm})$ & $\begin{array}{l}\text { Nominal thickness } \\
\text { of steel plate } t_{\mathrm{s}}(\mathrm{mm})\end{array}$ & $\begin{array}{c}\text { Total } \\
\text { number of cavities }\end{array}$ & $\begin{array}{c}\text { Specimen } \\
\text { height } h(\mathrm{~mm})\end{array}$ & $\begin{array}{l}\text { Nominal steel } \\
\text { content } \alpha(\%) \\
\end{array}$ \\
\hline 1 & YA4-600 & 50.00 & 2.00 & 4 & 600.00 & 13.40 \\
\hline 2 & YA5-600 & 50.00 & 2.00 & 5 & 600.00 & 13.10 \\
\hline
\end{tabular}

Note. Consider YA4-600 as an example to describe the numbering convention of shear wall specimens. Y indicates the cross section of multicavity steel tube self-compacting concrete shear wall, A (axially loaded) implies that the shear wall specimen is axially compressed, 4 indicates that the total number of cavities is 4 , and 600 indicates that the height of the shear wall specimen is $600 \mathrm{~mm}$.

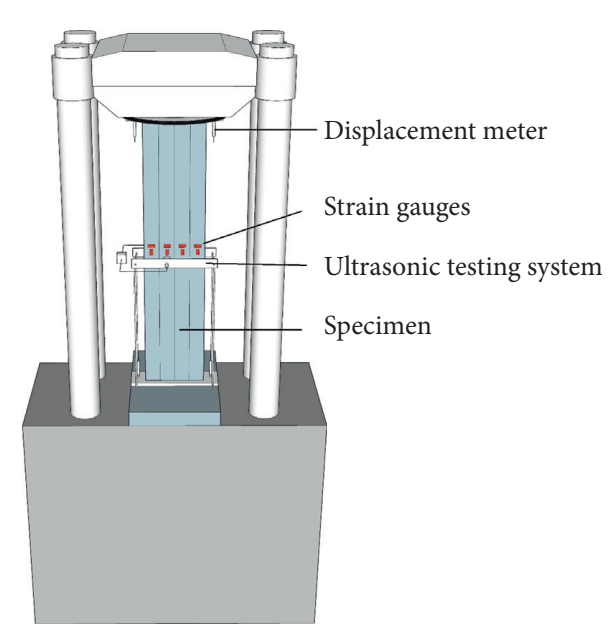

Figure 2: Loading and ultrasonic testing device.

under unidirectional load is employed for steel. This model is shown in Figure 6, and the relevant expression is provided in equation (1). The stress-strain relationship model obtained by decomposition analysis method is used for concrete:

$$
\sigma_{s}= \begin{cases}E_{s} \varepsilon_{s}, & \varepsilon_{s}<\varepsilon_{e}, \\ A \varepsilon_{s}^{2}+B \varepsilon_{s}+C, & \varepsilon_{e}<\varepsilon_{s} \leq \varepsilon_{e 1}, \\ f_{y}, & \varepsilon_{e 1}<\varepsilon_{s} \leq \varepsilon_{e 2}, \\ f_{y}\left[\frac{1+\left(\varepsilon_{s}-\varepsilon_{s 2}\right)}{\left(\varepsilon_{s 3}-\varepsilon_{s 2}\right)}\right], & \varepsilon_{e 2}<\varepsilon_{s} \leq \varepsilon_{e 3}, \\ 1.6 f_{y}, & \varepsilon_{s}>\varepsilon_{e 3},\end{cases}
$$

where $\quad \varepsilon_{e}=0.8 f_{\mathrm{y}} / E_{\mathrm{s}}, \quad \varepsilon_{e 1}=1.5 \varepsilon_{e}, \quad \varepsilon_{e 2}=10 \varepsilon_{1}, \quad \varepsilon_{\mathrm{e} 3}=100 \varepsilon_{1}$, $A=0.2 f_{\mathrm{y}} /\left(\varepsilon_{\mathrm{e} 1}-\varepsilon_{\mathrm{e} 2}\right)^{2}, B=2 A \varepsilon_{\mathrm{e} 1}$, and $C=0.8 f_{\mathrm{y}}+A \varepsilon_{\mathrm{e} 1}-B \varepsilon_{\mathrm{e}}$.

The stress-strain relationship for concrete is shown in equation (2). This equation effectively reflects the confining effect of steel tube on the concrete under axial compression:

$$
\begin{aligned}
& \sigma_{c}=\sigma_{u}\left[A \frac{\varepsilon}{\varepsilon_{0}}+B\left(\frac{\varepsilon}{\varepsilon_{0}}\right)^{2}\right] ; \quad \varepsilon \leq \varepsilon_{0}, \\
& \sigma_{c}=\sigma_{u}(1-q)+\sigma_{u} q\left(\frac{\varepsilon}{\varepsilon_{0}}\right)^{(0.2+\alpha)} ; \varepsilon>\varepsilon_{0},
\end{aligned}
$$

where 


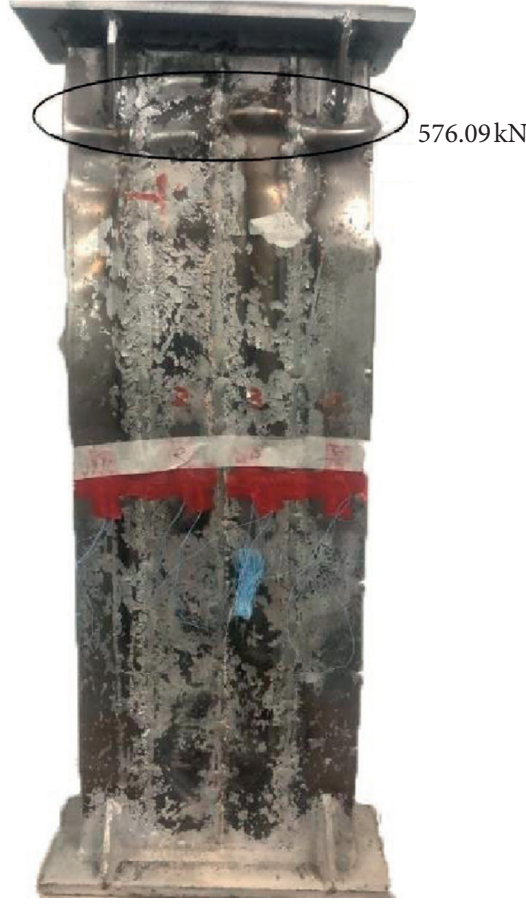

(a)

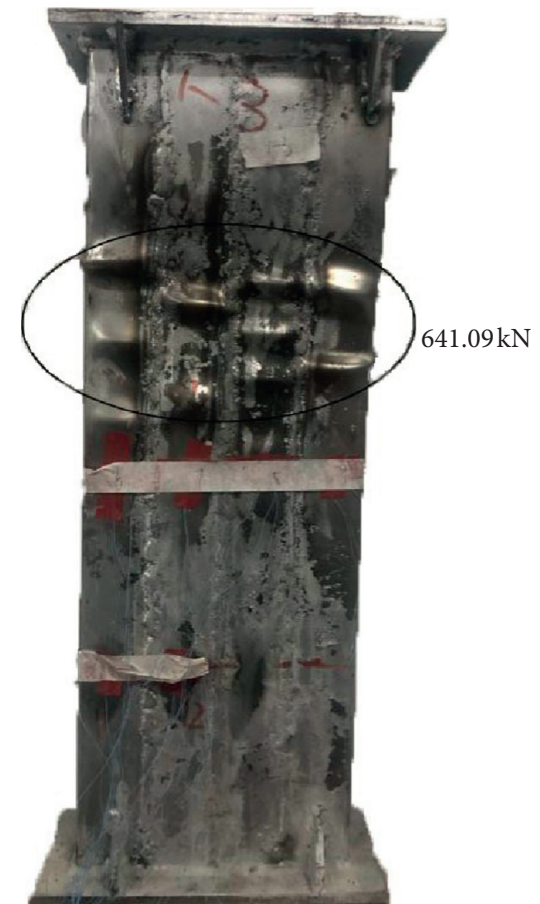

(b)

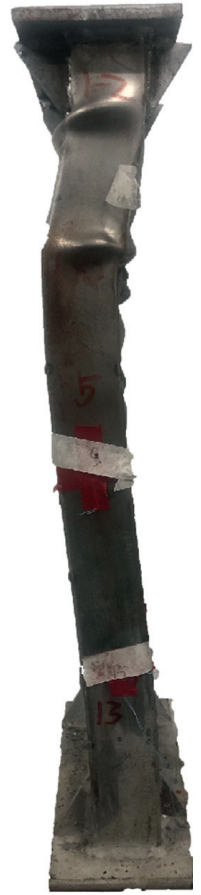

(c)

Figure 3: (a) Failure diagram of the third side of YA4-600 specimen; (b) failure diagram of the first side of YA4-600 specimen; (c) failure diagram of the second side of YA4-600 specimen.

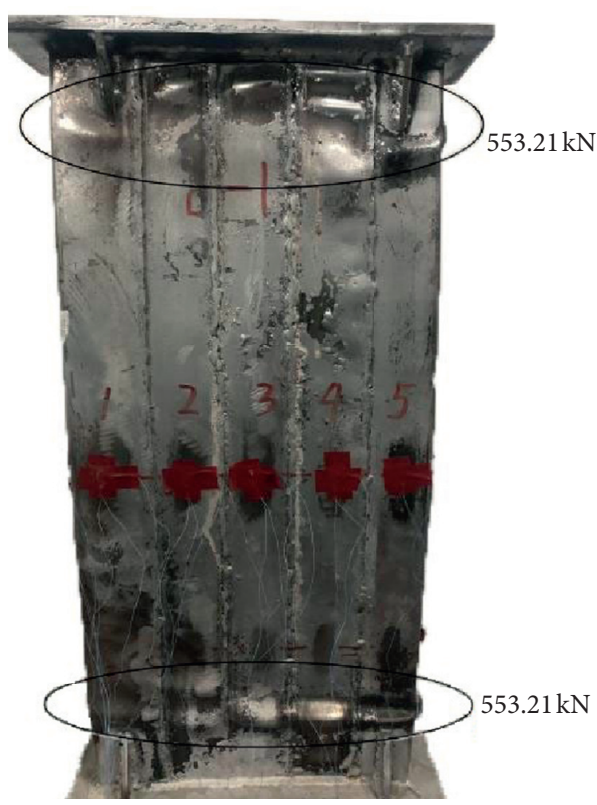

(a)

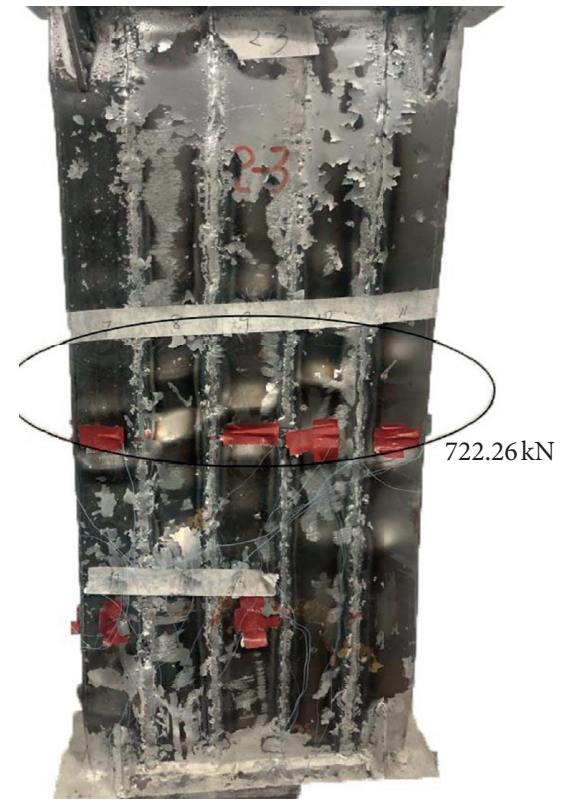

(b)

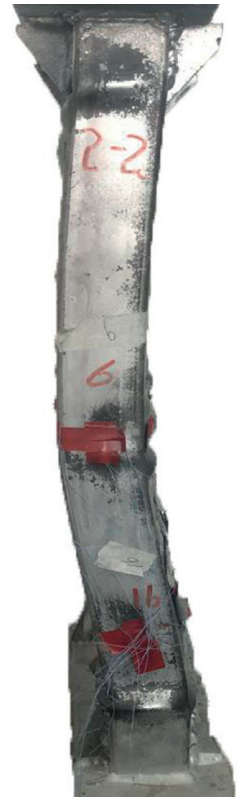

(c)

FIGURE 4: (a) Failure diagram of the third side of YA5-600 specimen; (b) failure diagram of the first side of YA5-600 specimen; (c) failure diagram of the second side of YA5-600 specimen. 


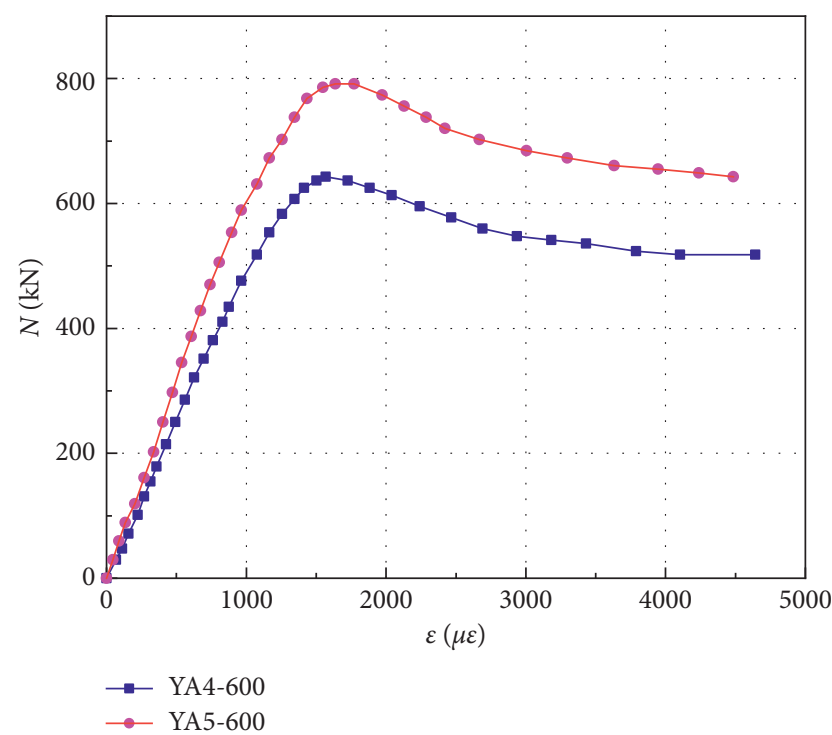

Figure 5: Load-strain curve of multicavity CFST shear wall specimens.

$$
\begin{aligned}
\sigma_{u} & =f_{\mathrm{ck}}\left[1+\left(\frac{30}{f_{\mathrm{cu}}}\right)^{0.4}\left(-0.0626 \xi^{2}+0.4848 \xi\right)\right] \\
\varepsilon_{0} & =\varepsilon_{c}+3600 \sqrt{\alpha}(\mu \varepsilon), \\
\varepsilon_{c} & =1300+10 f_{\mathrm{cu}}, \\
K & =\left(-5 \alpha^{2}+3 \alpha\right)\left(\frac{50-f_{\mathrm{cu}}}{50}\right)+\left(-2 \alpha^{2}+2.15 \alpha\right)\left(\frac{f_{\mathrm{cu}}-30}{50}\right), \\
q & =\frac{K}{0.2+\alpha} \\
f_{\mathrm{ck}} & =0.8 f_{\mathrm{cu}} \\
\xi & =\frac{\alpha f_{y}}{f_{\mathrm{ck}}} \\
\alpha & =\frac{A_{s}}{A_{c}} .
\end{aligned}
$$

Here, $f_{\mathrm{cu}}$ is the compressive strength of concrete cube $(\mathrm{MPa}), f_{\mathrm{ck}}$ is the standard value of axial compressive strength of concrete $(\mathrm{MPa}), \xi$ is the height of concrete relative to the compression zone, $\varepsilon_{0}$ is the hoop strain of concrete, $f_{\mathrm{y}}$ is the yield strength of steel $(\mathrm{MPa}), A_{\mathrm{s}}$ is the reinforcement area $\left(\mathrm{mm}^{2}\right)$, and $A_{\mathrm{c}}$ is the cross-sectional area of concrete $\left(\mathrm{mm}^{2}\right)$.

The 3D solid element C3D8R with 8-node hexahedral linearly reduced integral format is adopted for the concrete in steel tube, and S4R shell element with four-node reduced integral format is used for the steel tube. The interface contact between the multicavity steel tube and the selfcompacting concrete is considered as surface-to-surface contact based on ABAQUS finite element software, including a bonding slip in the tangential direction of the

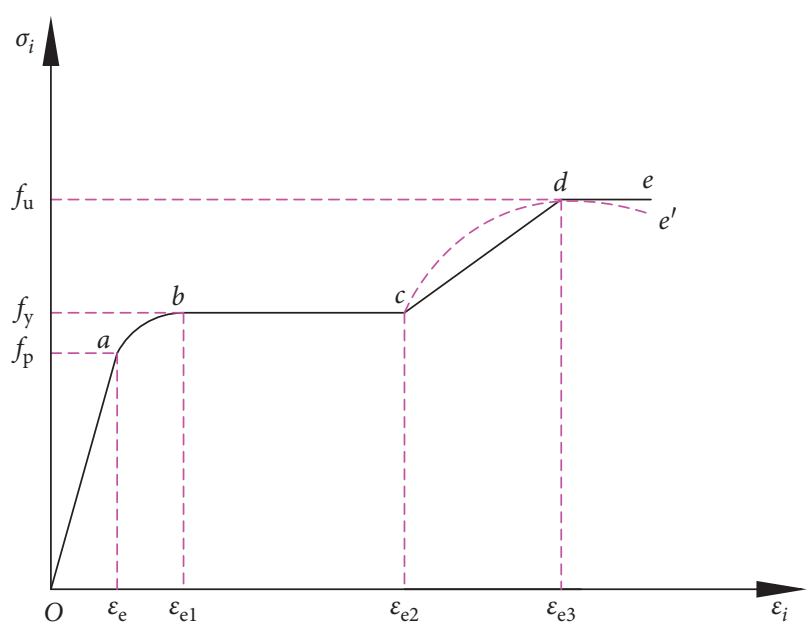

FIgURE 6: Five-stage constitutive relationship between stress and strain for steel.

interface and contact in the normal direction. The friction in the tangential direction of the model interface is modeled based on the Coulomb friction model. The main parameters include the critical shear stress $\tau_{\text {bond }}$ and friction coefficient $\mu$.

"Hard contact" is selected as the contact type in the normal direction of the interface between the steel tube and concrete. Any pressure between the contact surfaces can be transmitted to the inner surface, but the tensile force cannot be transmitted. When the pressure between the contact surfaces is zero, they can be separated. The finite element model of the multicavity CFST shear wall is shown in Figure 7.

During the axial compression test, to ensure the effective transfer of load and avoid dislocation between the contact surfaces, the inner concrete and end steel plate are bounded by "Tie," and a shell-to-solid coupling constraint is considered between the multicavity steel tube and the end steel plate. During the processing and transportation of specimen, the surface of multichamber steel tube can have some initial defects such as local buckling or depression, which may cause local buckling in the steel plate during axial compression, thereby reducing the bearing capacity of the specimen. To ensure the accuracy of ABAQUS-based finite element calculation, it is necessary to consider the initial defects in the model, i.e., the first-order buckling mode under the same boundary conditions, and then first-order buckling mode deformation is applied to the model according to $1 / 1000$ of the overall height.

4.2. Comparison between FEA Results and Test Results. In this study, all the shear wall specimens are analyzed by finite element method. A comparison between the load vs. strain curves obtained using FEA and experimental test is shown in Figure 8 .

It is clear from Figure 8 that the FEA results are in good agreement with the experimental results, which proves that the $3 \mathrm{D}$ nonlinear finite element model 


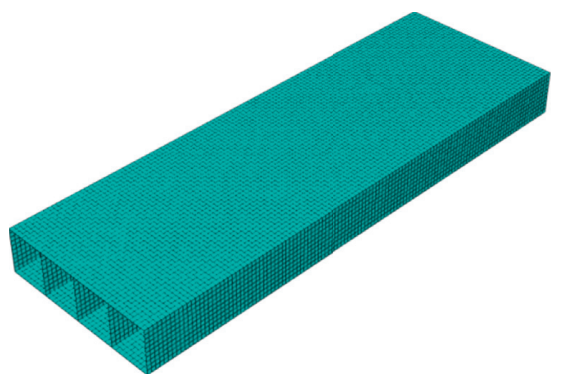

(a)

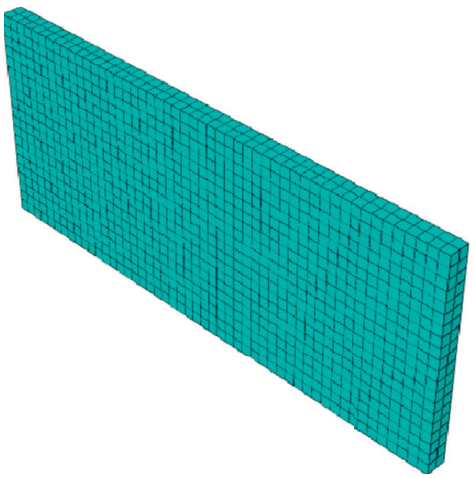

(c)

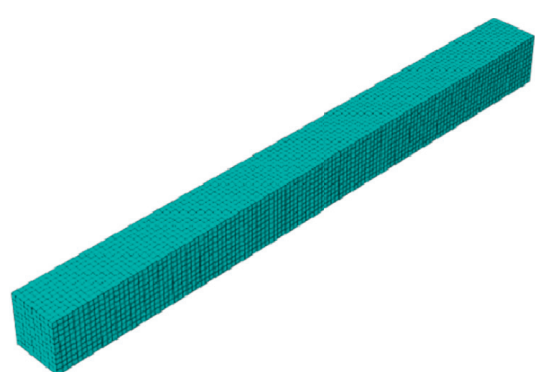

(b)

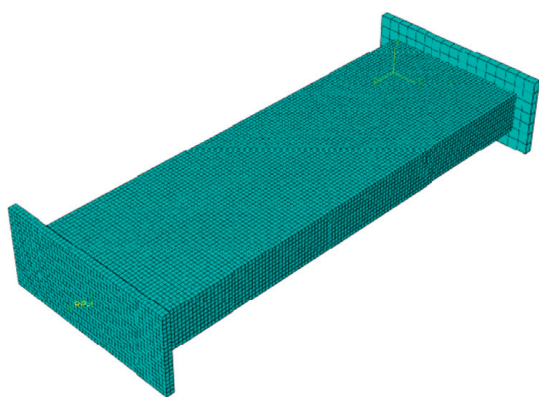

(d)

FIGURE 7: Schematic of (a) multicavity steel tube; (b) concrete; (c) end plate; (d) multicavity CFST shear wall.

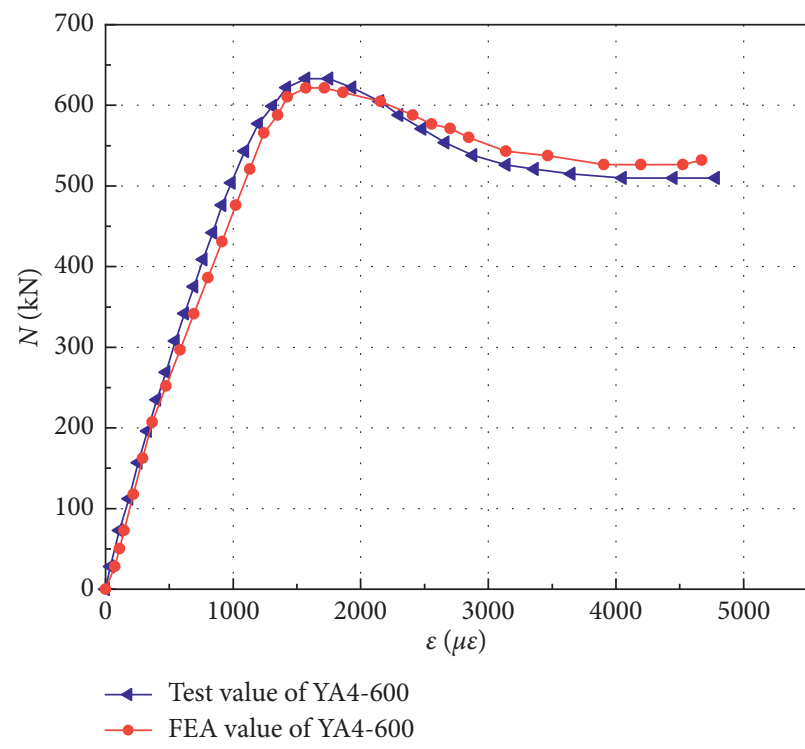

(a)

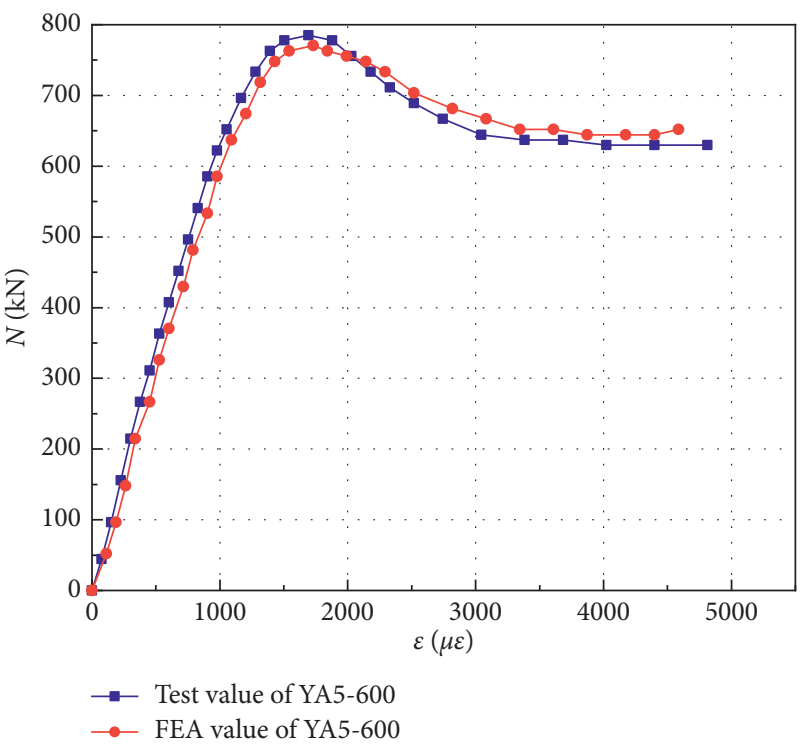

(b)

FIGURE 8: Comparison between the load-strain curves obtained based on FEA and experimental test for (a) specimen YA4-600; (b) specimen YA5-600.

established in this paper can effectively simulate the axial compression test of multicavity steel tube self-compacting concrete shear wall.

4.3. Axial Compressive Behavior. According to the FEA and experimental results, the axial compressive behavior of the self-compacting concrete shear wall of multicavity steel tube can be divided into three stages: elastic stage (OA), elasticplastic stage (OB), and failure stage (BC). Here, YA4-600 specimen is considered as an example to illustrate these stages. The load vs. longitudinal strain curve and deformation development of the specimen are shown in Figures 9 and 10 , respectively: 


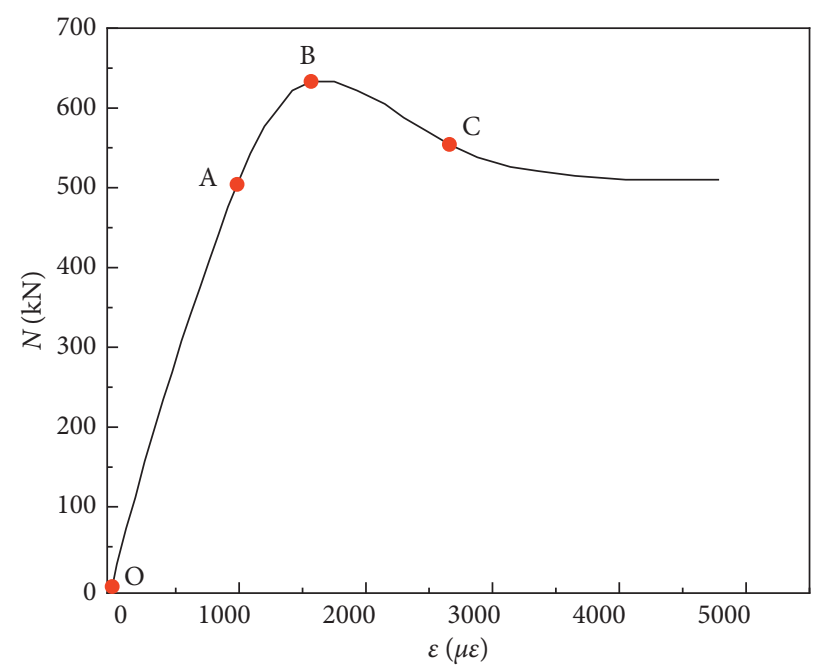

FIGURE 9: Load vs. longitudinal strain curve of YA4-600 specimen.

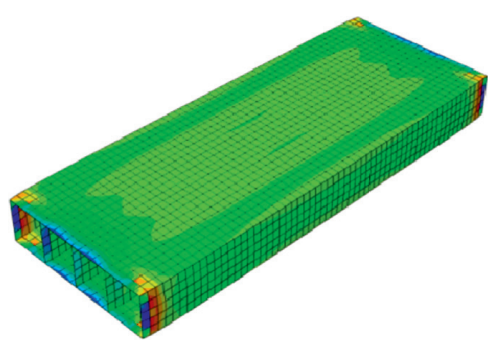

(a)

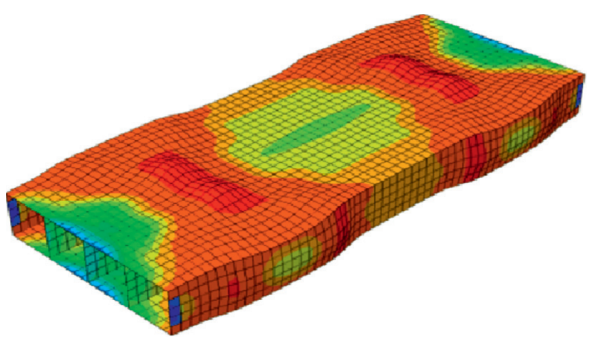

(b)

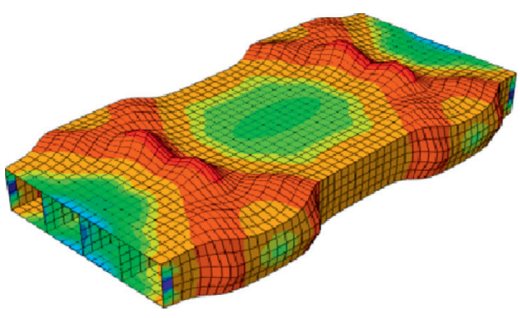

(c)

Figure 10: Deformation development in the YA4-600 specimen: (a) $N=0.7 N_{\mathrm{u}}$; (b) $N=N_{\mathrm{u}}$; (c) $N=0.85 N_{\mathrm{u}} \cdot N_{\mathrm{u}}$ is the maximum load-bearing capacity.

(1) Elastic stage (OA): the load-displacement curve at this stage is nearly linear until the stress of the steel tube reaches the proportional limit. At this stage, due to different Poisson's ratio $\mu_{s}$ of concrete and steel, the lateral deformation capacity of steel tube is greater than that of concrete. The steel tube and concrete are axially compressed independently and do not work together. Here, the bearing capacity of the member is equal to the simple superposition of load carrying capacity of built-in concrete and steel tube bundle. There is no bulging on the steel plate, as shown in Figure 10(a).

(2) Elastic-plastic stage $(\mathrm{AB})$ : the steel tube enters the elastic-plastic working stage. Since the elastic modulus of steel $\left(E_{\mathrm{s}}\right)$ continues to decrease at this stage, the elastic modulus of concrete does not change significantly, which causes the ratio of axial force distribution between the steel tube and core concrete to constantly change. The force on the concrete increases, while that on the steel tube decreases. When Poisson's ratio of the core concrete exceeds that of the steel tube, the interaction between steel tube and concrete begins to generate a tightening force $p$. At this time, the steel tube and concrete are in a 3D stress state, and the buckling phenomenon is more obvious in the middle of the member web drum, as shown in Figure 10(b).

(3) Failure stage (BC): at this stage, the load decreases with the increase in the longitudinal strain. Due to the rapid expansion of concrete, multiwave buckling at the surface of multicavity steel tube is more obvious, as shown in Figure 10(c). Since the concrete is constrained by the multicavity steel tube, the load vs. longitudinal strain curve gradually decreases at this stage, indicating that the self-compacting concrete shear wall member of the in-line multicavity steel tube has good ductility.

Figures 11-13 show the position of each feature point at a height of $\mathrm{H} / 2$ in the steel tube cavity, the stress-strain relationship curve at the central point of the web of the shear wall specimen, and the stress-strain relationship curve at the central point of the middle inner separator of the shear wall specimen, respectively.

It is clear from Figure 12 that the finite element results for the outer point of the web are in good agreement with the test results. During the early stage of loading, the shear wall specimen is in the elastic stage, and the internal and external surface stresses of the multicavity steel tube are almost 


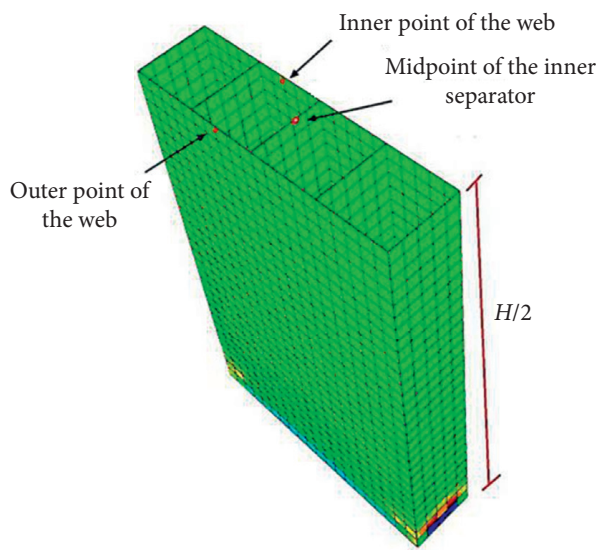

Figure 11: Location of each feature point at a height of $\mathrm{H} / 2$ in the steel tube cavity.

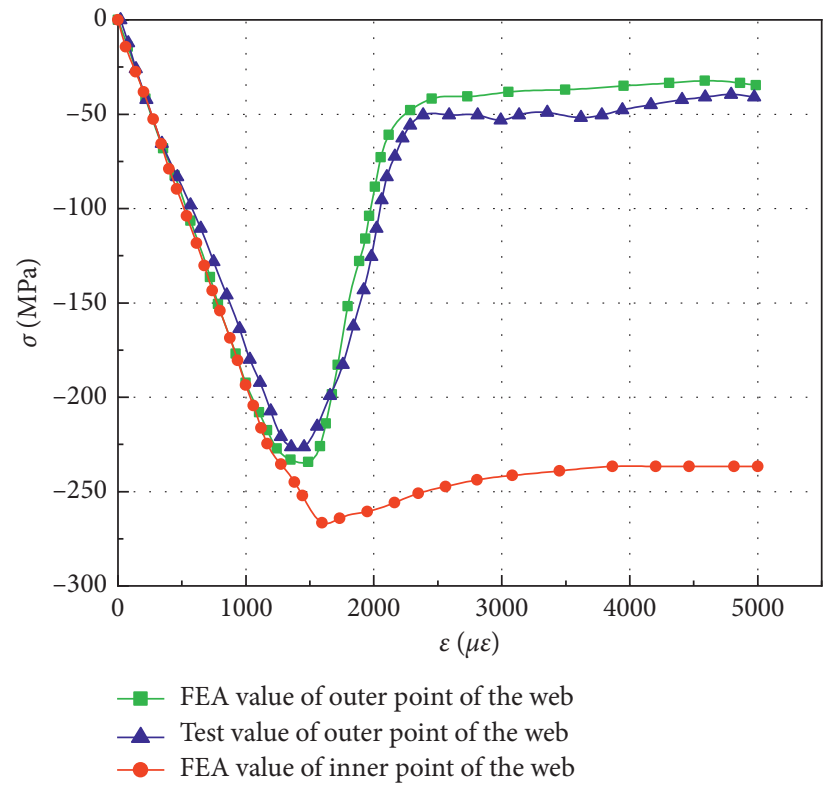

FIGURE 12: Stress-strain curve at the outer point of web of the shear wall specimen.

consistent, indicating that the web is in the axial deformation stage. At this stage, Figure 13 indicates that the longitudinal stress and Von Mises stress at the midpoint of the middle inner separator of the shear wall specimen increase linearly with the strain. When it reaches point $A$ in Figure 9, where the longitudinal strain is nearly $1100 \mu \varepsilon$, the stress is different on the inner and outer surfaces of the midpoint of the web. The stress on the outside of the steel tube wall begins to be larger than that on the inside of the steel tube wall, indicating that the local bending deformation of the web is initiated. In addition, it can be seen from Figure 13 that when the longitudinal strain is approximately $1100 \mu \varepsilon$, hoop stress begins to appear at the midpoint of the inner separator; the longitudinal stress reaches the peak point, and the Von Mises stress of the steel at the midpoint of the inner separator reaches the yield strength $f_{\mathrm{y}}=235 \mathrm{MPa}$. In addition, as the longitudinal strain increases, the hoop stress of the steel tube increases significantly, and the longitudinal stress decreases. This indicates that the lateral deformation of the concrete has started to exceed that of the steel tube. To limit the lateral deformation of concrete with multicavity steel tubes, the restraining effect of steel tube on the concrete is significantly increased, which leads to a considerable increase in the hoop stress of steel tubes. After the steel yields, it obeys the Von Mises yield criterion, and the Von Mises stress of the steel tube increases slightly with the increase in the longitudinal strain. Therefore, as the circumferential stress of the steel tube continues to increase, the longitudinal stress of the multicavity steel tube decreases.

Figure 14 shows the cloud diagram of longitudinal stress distribution of concrete when the multicavity CFST shear wall reaches the peak load $(631.06 \mathrm{kN})$, and the characteristic points are marked as black dots. Figure 15 shows the longitudinal stress vs. strain curve for each 


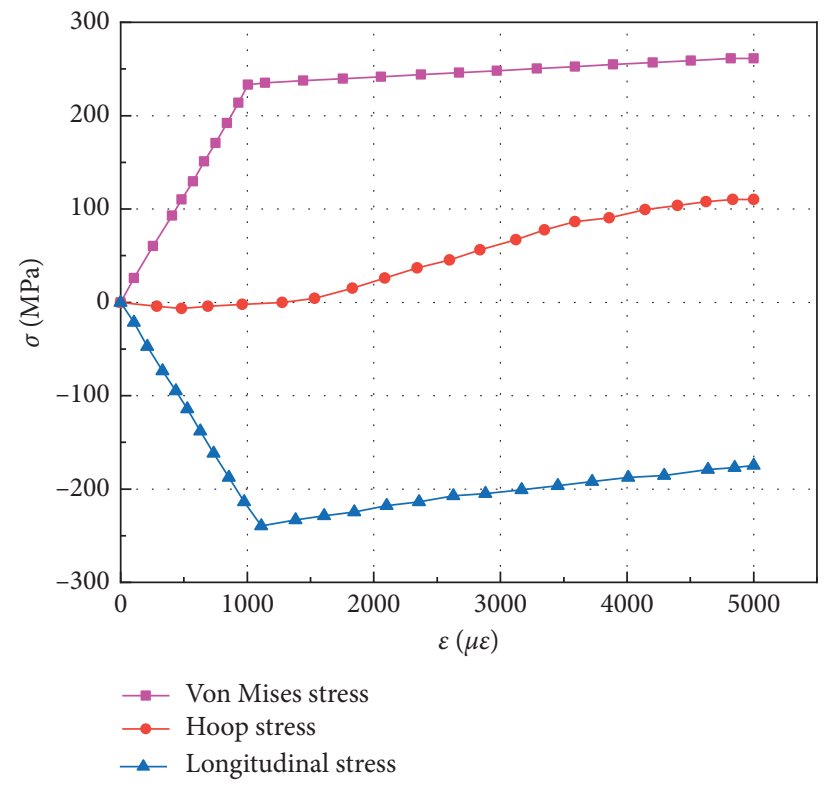

FIGURE 13: Stress-strain relationship curve for the mid-inner separator of the specimen.

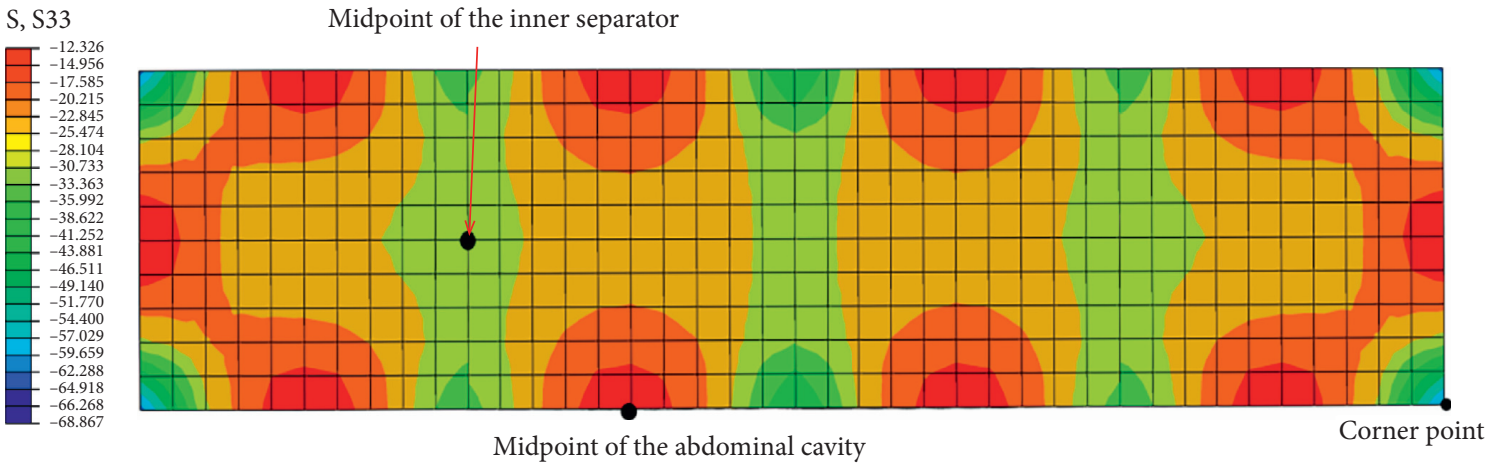

FIGURE 14: Cloud diagram of characteristic points and longitudinal stress distribution (H/2) of concrete.

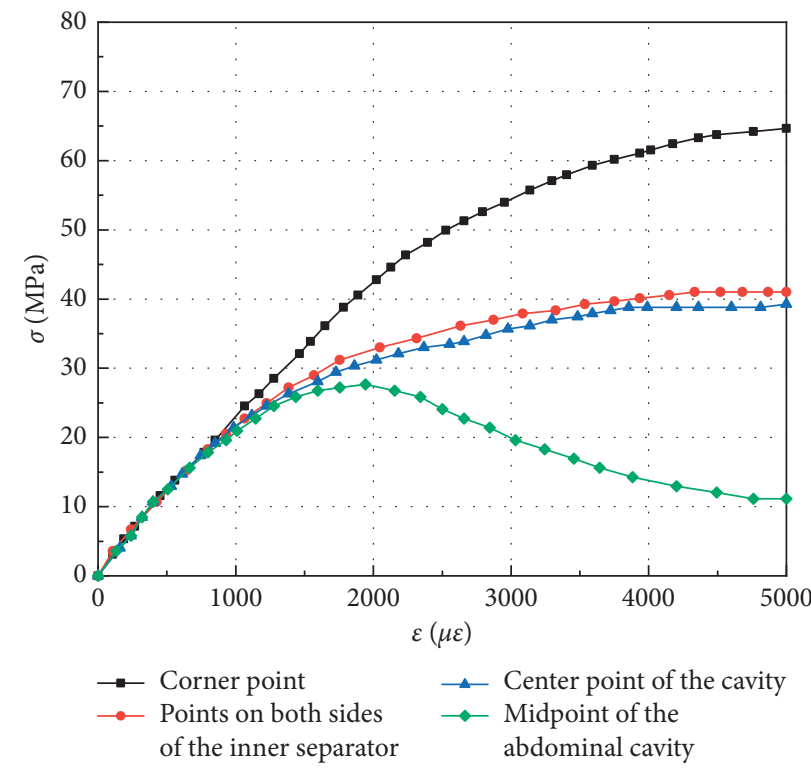

Figure 15: Relationship between longitudinal stress and strain at each point of concrete. 
point of the concrete. It can be concluded from Figures 14 and 15 that the stress level is the highest at the corner point in the multicavity CFST shear wall, which indicates that the constraining effect of multicavity steel tube on the corner points is the strongest, and the longitudinal stress is nearly $66 \mathrm{MPa}$. The stress level in the middle of the web is the lowest, only $\sim 25 \mathrm{MPa}$. The center point of a single cavity and the points on both sides of the inner separator are also greatly constrained by the steel tube, and the longitudinal stress is nearly $43 \mathrm{MPa}$. According to the mechanical mechanism of multicavity CFST shear wall, its axial compression mechanism is similar to that of the rectangular steel tube, but the concrete on both sides of the multicavity steel tube is also constrained by the steel tube due to the presence of inner separator.

According to the finite element method, parametric analysis is performed using ABAQUS software. The bearing capacity of multicavity CFST shear wall under axial compression load is obtained, as shown in Figure 16.

Consider Q235-C40-2 as an example. Here, Q235 indicates that the yield strength of steel is $235 \mathrm{MPa}$; C40 implies that the compressive strength of concrete is $40 \mathrm{MPa}$; 2 indicates that the thickness of the steel is $2 \mathrm{~mm}$.

\section{Calculation Formula for Bearing Capacity}

According to [40], the average value of the ratio of longitudinal compressive stress to yield strength of the steel tube is expressed as follows:

$$
\sigma_{L, s}=0.78 f_{s},
$$

where $\sigma_{\mathrm{L}, \mathrm{s}}$ is the longitudinal compressive stress of the steel tube and $f_{\mathrm{s}}$ is the yield strength of the steel tube.

According to Von Mises yield criterion, it can be obtained that

$$
\sigma_{\theta, s}=0.33 f_{s}
$$

where $\sigma_{\theta, \mathrm{s}}$ is the average value of the lateral stress when the steel tube is pulled.

According to the ABAQUS FEA results, the range of reinforced and non-reinforced areas can be obtained from the cloud diagram of the multicavity self-compacting concrete shear wall in Figure 17. The multicavity steel tube mainly restrains the four corners and center of the concrete. The radius of the confinement area is $0.2 \mathrm{~b}$ ( $\mathrm{b}$ is the side length of single cavity of the multicavity steel tube). The calculation diagram is shown in Figure 18.

The multicavity steel tube is divided into end column and web. For the end column, the non-reinforced and reinforced areas of the concrete are represented by equation (6) and (7), respectively.

$$
\begin{aligned}
A_{c 1, d} & =1.5 \pi r^{2} \\
& =0.1884 A_{c}, \\
A_{c 2, d} & =(1-0.1884) A_{c} \\
& =0.8116 A_{c},
\end{aligned}
$$

where $A_{\mathrm{c} 1, \mathrm{~d}}$ is the non-reinforced area of concrete; $A_{\mathrm{c} 2, \mathrm{~d}}$ is the reinforced area of concrete; and $A_{\mathrm{c}}$ is the concrete area.

The lateral stress of concrete in the non-reinforced area is neglected. According to the theory of limit equilibrium, the lateral restraining force $\sigma_{\mathrm{r}, \mathrm{c}}$ of the concrete in the reinforced area and the transverse force $\sigma_{\mathrm{r}, \mathrm{s}}$ of the steel tube are in equilibrium. The relationship between transverse stress of the steel tube and lateral stress of the reinforced concrete is given as follows:

$$
\sigma_{r, c}=\frac{2 t \sigma_{r, s}}{b}
$$

According to the above analysis, in the non-reinforced area, the axial compressive strength of concrete is approximately equal to the axial compressive strength $f_{\mathrm{c}}$ of plain concrete. In the reinforced area, because the concrete is constrained by the steel tube, the axial compressive strength of concrete is significantly improved. This improvement can be expressed by formula (9). The bearing capacity $N_{u}$ of the component includes the axial load capacity $N_{\mathrm{d}}$ of the end column and the axial load capacity $N_{\mathrm{f}}$ of the web, as shown in formula (10).

$$
\begin{aligned}
& \sigma_{L, c}=f_{c}+k \sigma_{r, c}, \\
& N_{u}=N_{d}+N_{f} .
\end{aligned}
$$

Here, $\sigma_{\mathrm{L}, \mathrm{c}}$ is the axial compressive strength of concretefilled in the reinforced area and $k$ is the lateral compression coefficient, which is considered as 3.4 according to [41].

The axial compressive bearing capacity of the end column is composed of three parts: axial compressive bearing capacity $f_{\mathrm{c}, \mathrm{d}} A_{\mathrm{c} 1, \mathrm{~d}}$ of concrete in the non-reinforced area, axial compressive bearing capacity $\sigma_{\mathrm{L}, \mathrm{c}, \mathrm{d}} A_{\mathrm{c} 2, \mathrm{~d}}$ of concrete in the reinforced area, and axial compression bearing capacity $\sigma_{\mathrm{L}, \mathrm{s}, \mathrm{d}} A_{\mathrm{s}, \mathrm{d}}$ of multicavity steel tube, as shown in equation (11).

$$
N_{d}=f_{c, d} A_{c 1, d}+\sigma_{L, c, d} A_{c 2, d}+\sigma_{L, s, d} A_{s, d} .
$$

Reorganizing the above equation, it can be obtained that

$$
N_{d}=A_{c, d} f_{c, d}+9.1 f_{s} \text { bt. }
$$

The above equation can be used to calculate the common bearing capacity of the two end columns, and to simplify the calculation, one side is included in the web calculation.

The axial compressive bearing capacity of the web is composed of three parts: axial compressive bearing capacity $f_{\mathrm{c}, \mathrm{f}} A_{\mathrm{c} 1, \mathrm{f}}$ of concrete in the non-reinforced area, axial compressive bearing capacity $\sigma_{\mathrm{L}, \mathrm{c}, \mathrm{f}} A_{\mathrm{c} 2, \mathrm{f}}$ of concrete in the reinforced area, and xial compressive bearing capacity $\sigma_{\mathrm{L}, \mathrm{s}, \mathrm{f}} A_{\mathrm{s}, \mathrm{f}}$ of multicavity steel tube, as shown in equation (13).

$$
N_{f}=f_{c, f} A_{c 1, f}+\sigma_{L, c, f} A_{c 2, f}+\sigma_{L, s, f} A_{s, f} .
$$

Simplifying the above equation, one gets

$$
N_{f}=A_{c, f} f_{c, f}+4.16 f_{s} b t .
$$

The above equation can be used to calculate the bearing capacity of the web. 


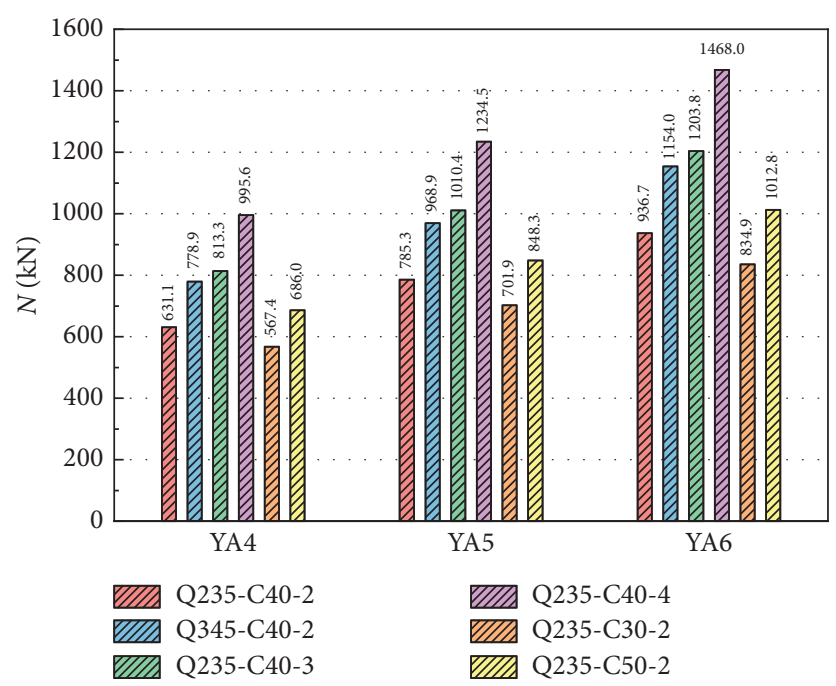

FIgURE 16: Axial load capacity under different parameters.

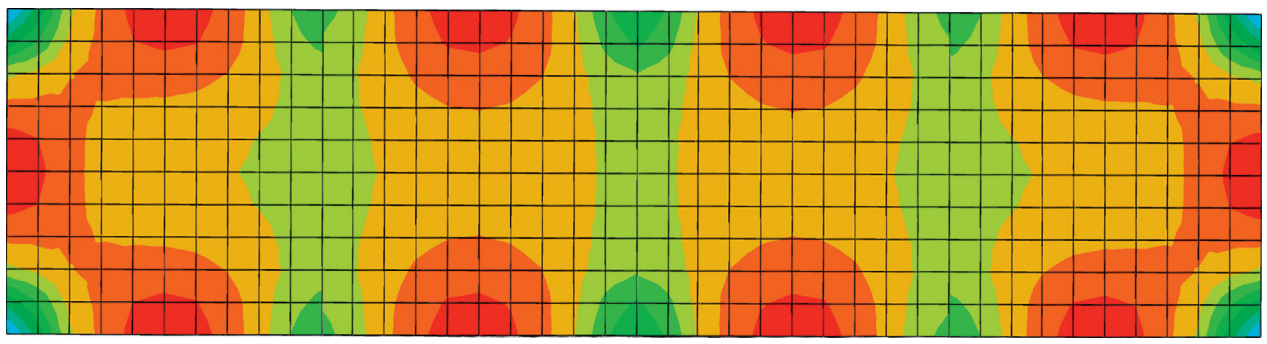

Figure 17: Cloud diagram of in-line multicavity steel tube self-compacting concrete shear wall.

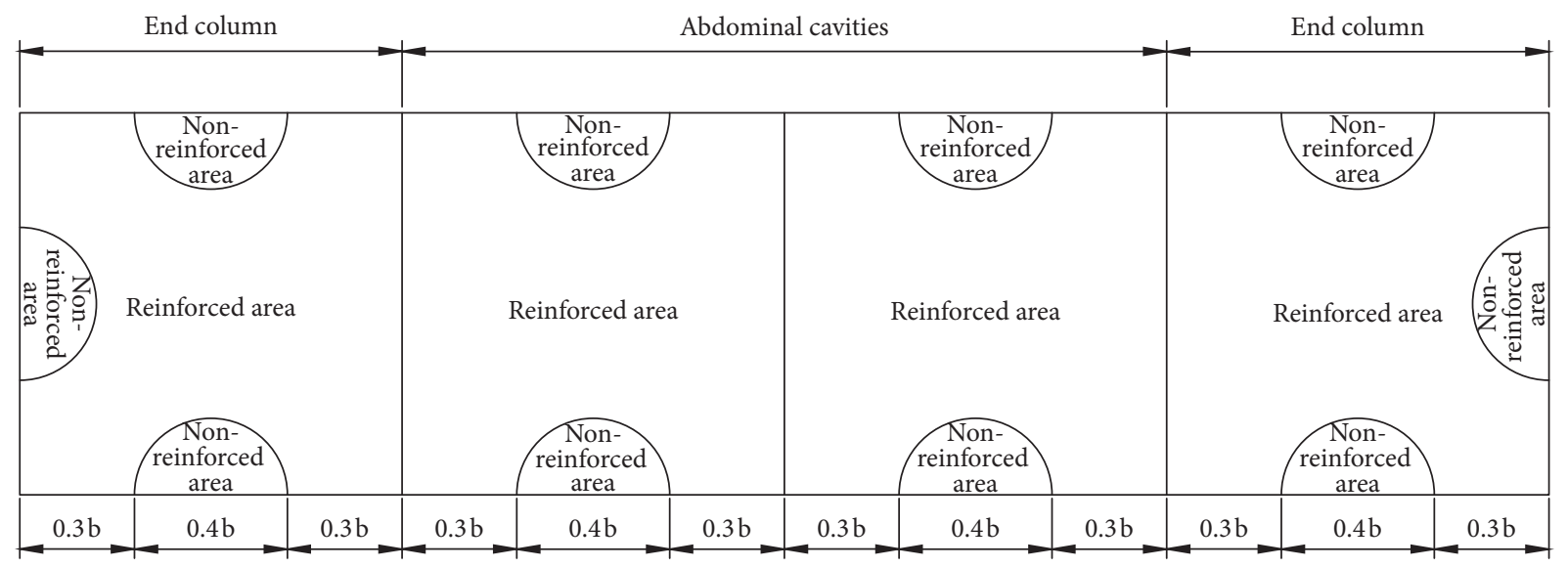

FIGURE 18: Schematic for calculating the bearing capacity of multicavity steel tube self-compacting concrete shear wall.

Using equations (12) and (14), the bearing capacity $N_{u}$ can be obtained as follows:

$$
N_{u}=A_{c} f_{c}+(4.16 n-0.78) f_{s} \mathrm{bt}, \quad n \geq 4,
$$

where $n$ is the number of cavities.

According to the above equation, the calculated value is nearly $15 \%$ larger than the test value, which may be attributed to the fact that the initial defects of the multicavity steel tube are not taken into account in the calculation.
During the processing and transportation of multicavity steel tube specimen, manual cutting, welding errors, and collisions can cause irregular deformation of the steel tube, which may introduce some initial defects, and bias occurs during the loading process. Consequently, the load-bearing capacity of the shear wall specimen is reduced. The second reason is that the influence of steel tube weld is not considered. The third reason is the limitation of the specimen size. The shape of the specimen is complicated, which can affect the compactness of the self-compacting concrete to a 
certain extent. Therefore, a correction factor of 0.85 is introduced, as shown in equation (16).

$$
N_{u}=0.85 A_{c} f_{c}+(3.536 n-0.663) f_{s} b t, \quad n \geq 4 .
$$

The final comparison between calculated and FEA results is shown in Table 3 .

It can be seen from Table 3 that the finite element simulation results are in good agreement with the calculation results, which proves that the above equation can serve as a technical reference for practical engineering.

\section{Ultrasonic Wave Testing on the Damage Condition of CFST}

The cumulative damage of core concrete in the steel tube inevitably causes development of cracks under axial loading, and the concrete cracks can absorb and dissipate ultrasonic wave energy. When ultrasonic waves pass through these defects, they are attenuated, which causes a reduction in the wave speed. Therefore, ultrasonic technology can be used to detect the damage state of CFST under axial loading.

6.1. Testing Device. A $2000 \mathrm{kN}$ press was used for this test, and the loading method is described in Section 2.3. The ultrasonic test of concrete was conducted on a NM-4A nonmetallic ultrasonic testing analyzer (Koncrete Company, Beijing, China).

The plane transducer of the ultrasonic detector was fixed at the center of the steel tube with a bracket. To maintain a close contact between the plane transducer and the surface of the steel tube, the surface at the center of the steel pipe was polished and evenly coated with Vaseline.

6.2. Loading Steps. The specific steps of the test are as follows:

(1) The test piece was placed in the working area of the press for debugging and centering.

(2) The plane transducer was fixed at the center of the specimen by the bracket and was connected to the ultrasonic detector.

(3) The specimen was preloaded. It was checked whether the instruments are working properly, and then the specimen was unloaded.

(4) The data were collected at a load interval of $50 \mathrm{kN}$, and the apparent deformation of the specimen was recorded.

6.3. Relationship between Axial Load and Maximum Amplitude. The relationship between maximum amplitude value of the waveform for the specimens YA4-600 and YA5600 and the axial load is shown in Figure 19.

It is clear from Figure 19 that when the axial load is $0-150 \mathrm{kN}$, the maximum amplitude of YA4-600 specimen exhibits a slow decreasing trend, indicating that the crack expansion of the core concrete inside the steel tube is not obvious. When the axial load is $150-450 \mathrm{kN}(\sim 0.7 \mathrm{Nu})$, the maximum amplitude of YA4-600 tends to decrease significantly, which indicates that more cracks develop in the concrete rapidly. When the axial load is $450-650 \mathrm{kN}(\sim \mathrm{Nu})$, the maximum amplitude of YA4-600 specimen shows an increasing trend, which indicates that the core concrete becomes more dense during this loading phase. This is because as the axial pressure increases, Poisson's ratio of the concrete gradually increases and exceeds Poisson's ratio of the steel tube. At this time, the steel tube generates a tightening force $p$ on the concrete under the axial pressure, which causes a tightening force on the steel tube in the $3 \mathrm{D}$ stress state, limiting the expansion of the internal cracks of concrete, and the concrete becomes dense under axial pressure. As the loading continues, the bearing capacity of the CFST gradually decreases, and the displacement continues to increase. When the load is $650-700 \mathrm{kN}$, the maximum amplitude drops significantly, which indicates that the steel tube can no longer limit the cracking of the core concrete, and the CFST specimen is destroyed. When the axial load is $0-200 \mathrm{kN}$, the maximum amplitude of YA5-600 specimen is not reduced significantly, which suggests that the crack expansion of the core concrete inside the steel tube is not obvious. When the axial load is $150-450 \mathrm{kN}(\sim 0.7 \mathrm{Nu})$, the maximum amplitude of YA5-600 specimen tends to decrease significantly, which indicates that more cracks develop in the core concrete rapidly. When the axial load is $550-800 \mathrm{kN}(\sim \mathrm{Nu})$, the maximum amplitude of YA5-600 increases with the increase in the axial load, which indicates that the core concrete becomes more dense during this loading phase. When the load is $800-850 \mathrm{kN}$, the maximum amplitude drops significantly, which suggests that the steel tube can no longer limit the cracking of the core concrete, and the CFST specimen is destroyed. According to Figure 19, the damage state of core concrete under the axial load changes in a three-stage pattern, and the steel tube starts to play a binding role for the core concrete when the load is nearly $0.7 \mathrm{Nu}$.

6.4. Relationship between Axial Load and Wave Speed. According to the established fact that ultrasonic waves bypass the defect areas and propagate along the smallest path, such waves can be used to detect the internal damage and crack propagation of CFST. In general, the propagation speed of ultrasonic waves in steel and concrete is $4000-6000 \mathrm{~m} / \mathrm{s}$. When the load is 0 , the propagation speed and time taken by the ultrasonic waves to travel through the specimen are shown in Table 4.

When the axial load is applied, the cracks inside the CFST develop gradually, and the path of ultrasonic waves passing through the steel tube and concrete changes, which is directly reflected as a change in the ultrasonic time-offlight and wave speed. During the loading process, damage factor $D$ is introduced to assess the damage state of the specimen. The initial value of $D$ of the CFST is considered as 0 . The damage factor $D$ is calculated as follows:

$$
\mathrm{D}=1-\left(\frac{\mathrm{V} 1}{\mathrm{~V} 0}\right) 2 \text {, }
$$


TABLe 3: Comparison between calculated and FEA results.

\begin{tabular}{|c|c|c|c|c|c|c|c|}
\hline Number & $f_{\mathrm{c}}(\mathrm{MPa})$ & $f_{\mathrm{s}}(\mathrm{MPa})$ & $n$ & $t(\mathrm{~mm})$ & Calculated value $(\mathrm{kN})$ & FEA value $(\mathrm{kN})$ & Difference value (\%) \\
\hline YA4-600-1 & 38.17 & 235.00 & 4 & 2.00 & 641.25 & 631.06 & 1.62 \\
\hline YA4-600-2 & 38.17 & 345.00 & 4 & 2.00 & 789.54 & 778.86 & 1.37 \\
\hline YA4-600-3 & 38.17 & 235.00 & 4 & 3.00 & 799.65 & 813.31 & -1.68 \\
\hline YA4-600-4 & 38.17 & 235.00 & 4 & 4.00 & 958.05 & 995.63 & -3.78 \\
\hline YA4-600-5 & 30.80 & 235.00 & 4 & 2.00 & 578.60 & 567.42 & 1.97 \\
\hline YA4-600-6 & 44.00 & 235.00 & 4 & 2.00 & 690.80 & 685.98 & 0.70 \\
\hline YA5-600-1 & 38.17 & 235.00 & 5 & 2.00 & 805.46 & 785.31 & 2.57 \\
\hline YA5-600-2 & 38.17 & 345.00 & 5 & 2.00 & 992.64 & 968.89 & 2.45 \\
\hline YA5-600-3 & 38.17 & 235.00 & 5 & 3.00 & 1005.41 & 1010.42 & -0.50 \\
\hline YA5-600-4 & 38.17 & 235.00 & 5 & 4.00 & 1205.36 & 1234.52 & -2.36 \\
\hline YA5-600-5 & 30.80 & 235.00 & 5 & 2.00 & 727.15 & 701.89 & 3.60 \\
\hline YA5-600-6 & 44.00 & 235.00 & 5 & 2.00 & 867.40 & 848.33 & 2.25 \\
\hline YA6-600-1 & 38.17 & 235.00 & 6 & 2.00 & 969.66 & 936.72 & 3.52 \\
\hline YA6-600-2 & 38.17 & 345.00 & 6 & 2.00 & 1195.75 & 1153.98 & 3.62 \\
\hline YA6-600-3 & 38.17 & 235.00 & 6 & 3.00 & 1211.16 & 1203.79 & 0.61 \\
\hline YA6-600-4 & 38.17 & 235.00 & 6 & 4.00 & 1452.66 & 1467.96 & -1.04 \\
\hline YA6-600-5 & 30.80 & 235.00 & 6 & 2.00 & 875.70 & 834.93 & 4.88 \\
\hline YA6-600-6 & 44.00 & 235.00 & 6 & 2.00 & 1044.00 & 1012.82 & 3.08 \\
\hline
\end{tabular}

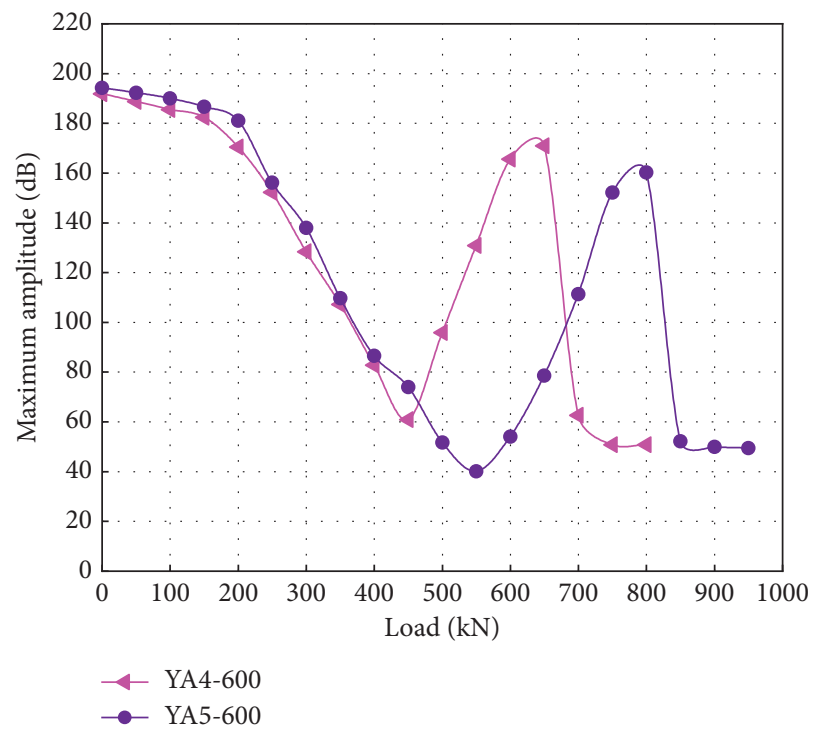

Figure 19: Effect of load on maximum amplitude of the specimens.

TABLE 4: Ultrasonic test results of specimens under zero axial load.

\begin{tabular}{lccccc}
\hline Number & $\begin{array}{c}\text { Specimen } \\
\text { number }\end{array}$ & $\begin{array}{c}\text { Cavity thickness } t_{\mathrm{w}} \\
(\mathrm{mm})\end{array}$ & $\begin{array}{c}\text { Nominal thickness of steel plate } t_{\mathrm{s}} \\
(\mathrm{mm})\end{array}$ & $\begin{array}{c}\text { Ultrasonic time-of-flight } t \\
(\mu \mathrm{s})\end{array}$ & $\begin{array}{c}\text { Wave speed } v \\
(\mathrm{~m} / \mathrm{s})\end{array}$ \\
\hline 1 & YA4-600 & 50.0 & 2.0 & 11.1 & 4510.4 \\
2 & YA5-600 & 50.0 & 2.0 & 10.9 & 4571.8 \\
\hline
\end{tabular}

where $V_{0}$ is the initial wave velocity through the CFST when there is no axial load and $V_{1}$ is the damage wave velocity through the CFST after the axial load is applied.

The calculated values of $D$ are shown in Table 5 .

It is evident from Table 5 that as the axial load increases, the wave velocity through the CFST decreases continuously, and the damage factor $D$ increases continuously. The larger the damage factor $D$, the stronger the crack development and the more serious the damage inside the CFST.
6.5. Ultrasonic Spectral Analysis of Specimens. The amplitude spectra of the specimens YA4-600 and YA5-600 were obtained by performing fast Fourier transform on the measured sound wave. These spectra are shown in Figures 20 and 21.

It is clear from these figures that the frequency spectrograms of CFST exhibit a double-peak structure, and the corresponding frequencies are approximately $25 \mathrm{kHz}$ and $40 \mathrm{kHz}$. There are two main paths for ultrasonic waves to 
TABLE 5: Damage value under axial loading history.

\begin{tabular}{lcccc}
\hline Specimen number & Peak load & Initial wave speed $V_{0}(\mathrm{~m} / \mathrm{s})$ & Damage wave speed $V_{0}(\mathrm{~m} / \mathrm{s})$ & Damage factor $D$ \\
\hline YA4-600 & \multirow{2}{*}{$0.3 N_{\mathrm{u}}$} & 4510.4 & 4325.3 & 0.0804 \\
YA5-600 & \multirow{2}{*}{$0.5 N_{\mathrm{u}}$} & 4571.8 & 3329.5 & 0.1032 \\
\hline YA4-600 & \multirow{2}{*}{$0.7 N_{\mathrm{u}}$} & 4510.4 & 3834.4 & 0.2612 \\
YA5-600 & \multirow{2}{*}{$N_{\mathrm{u}}$} & 4571.8 & 3288.7 & 0.2966 \\
\hline YA4-600 & 4510.4 & 3356.5 & 0.4684 \\
YA5-600 & \multirow{2}{*}{$0.85 N_{\mathrm{u}}$} & 4571.8 & 3414.0 & 0.4610 \\
YA4-600 & 4510.4 & 3528.1 & 0.4271 \\
YA5-600 & 4571.8 & 2842.3 & 0.4045 \\
YA4-600 & 4510.4 & 2686.2 & 0.6029 \\
YA5-600 & 4571.8 & & 0.6548 \\
\hline
\end{tabular}

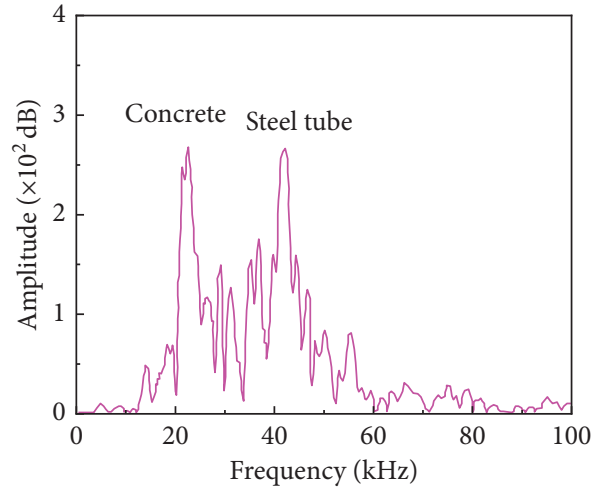

(a)

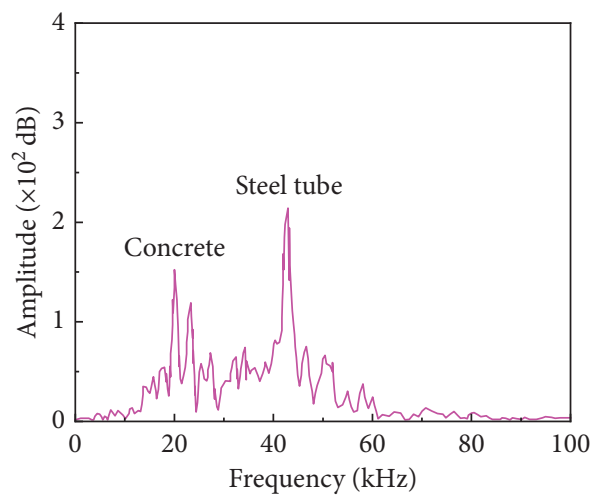

(c)

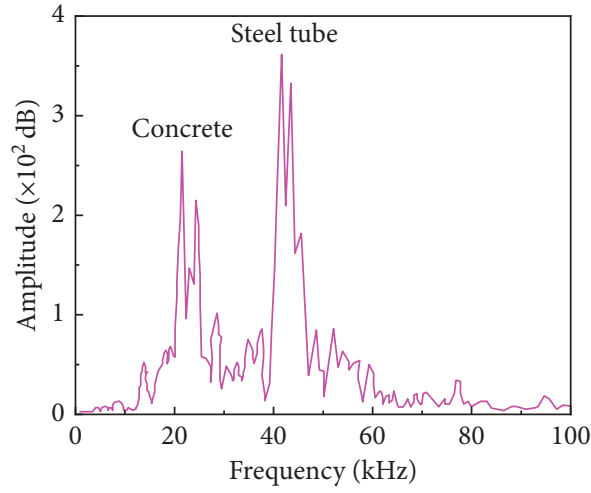

(e)

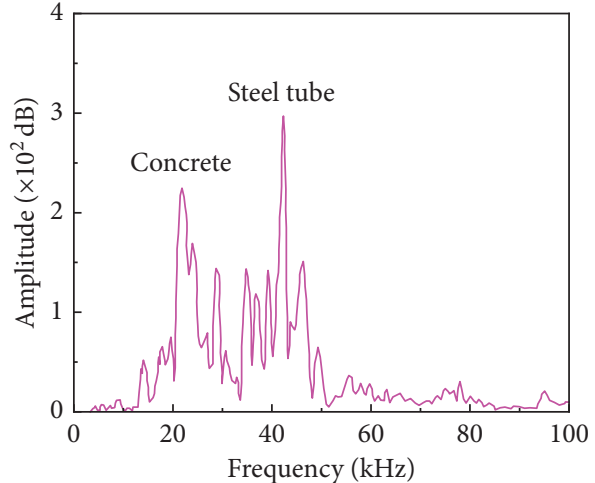

(b)

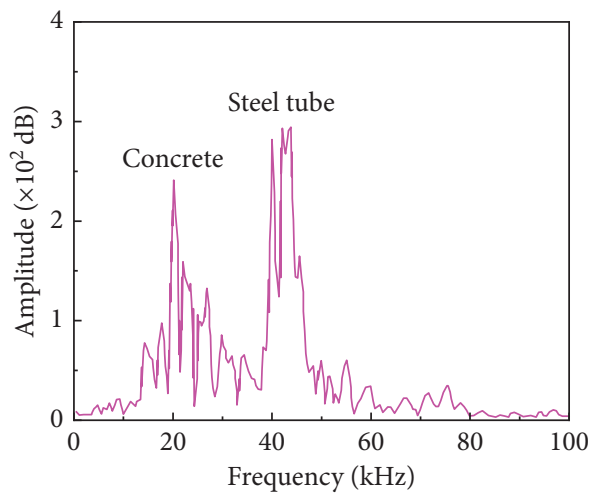

(d)

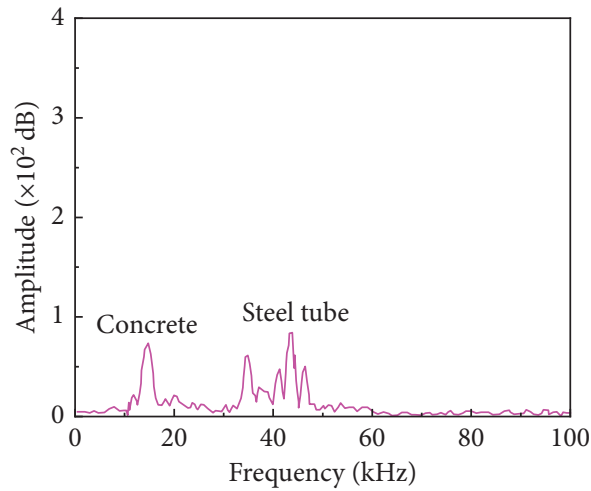

(f)

Figure 20: Ultrasonic frequency spectrograms of YA4-600 specimen under different axial loads: (a) 0 ; (b) $0.3 N_{\mathrm{u}}$; (c) $0.5 N_{\mathrm{u}}$; (d) $0.7 N_{\mathrm{u}}$; (e) $N_{\mathrm{u}}$; (f) $0.85 N_{\mathrm{u}}$. 


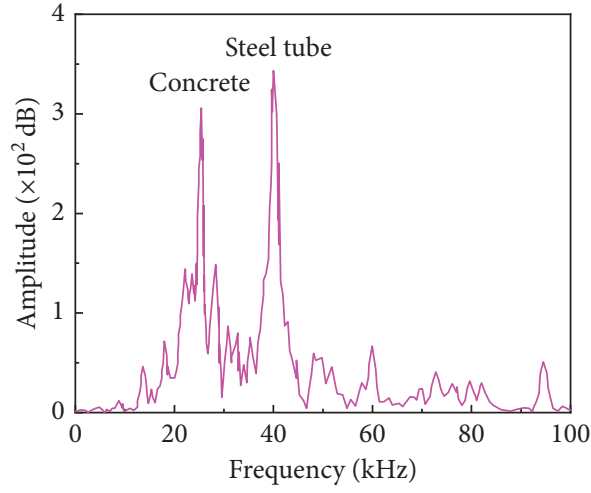

(a)

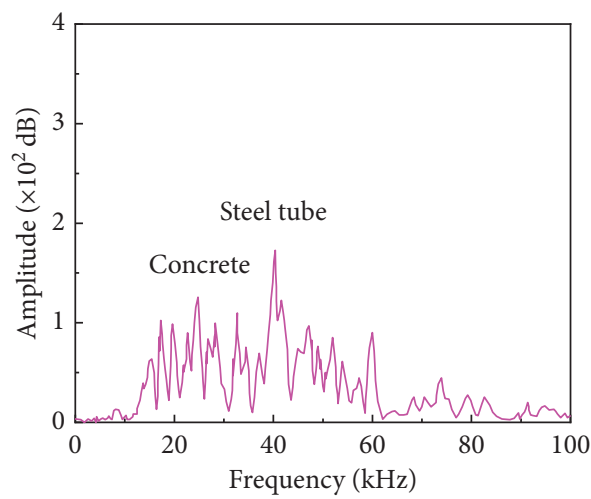

(c)

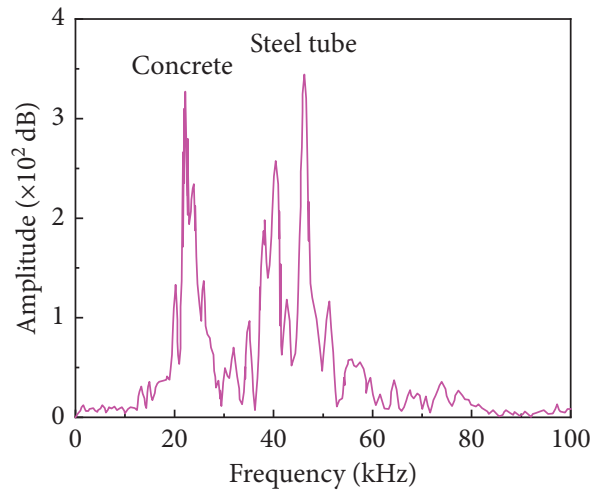

(e)

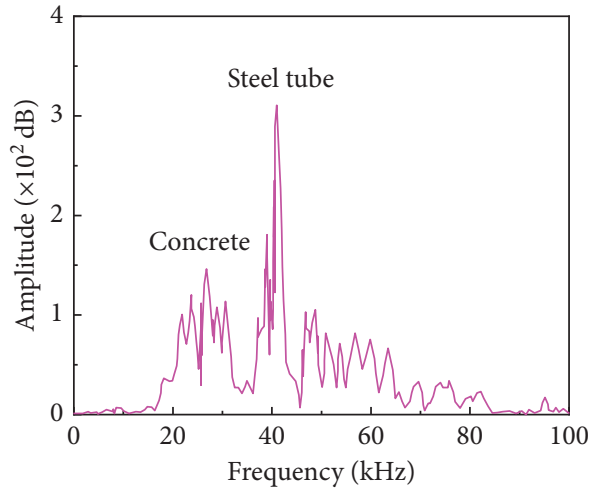

(b)

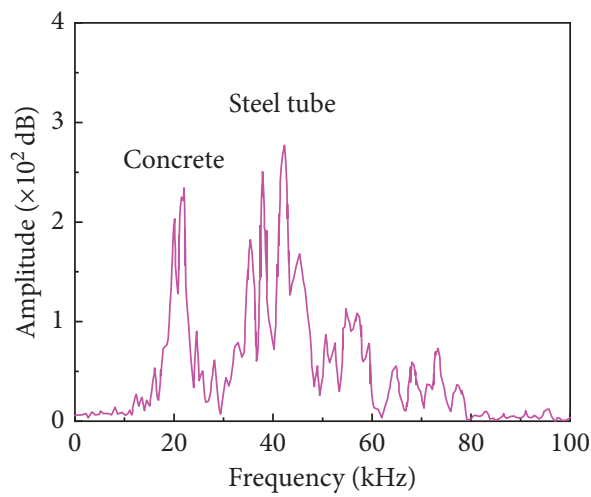

(d)

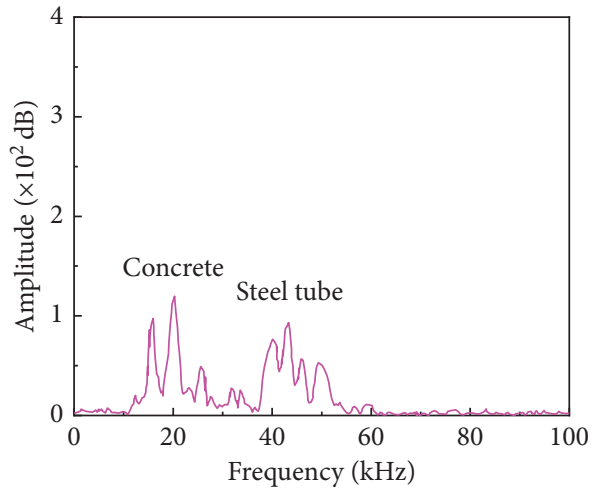

(f)

FiguRe 21: Ultrasonic frequency spectrograms of YA5-600 specimen under different axial loads: (a) 0 ; (b) $0.3 N_{\mathrm{u}}$; (c) $0.5 N_{\mathrm{u}}$; (d) $0.7 N_{\mathrm{u}}$; (e) $N_{\mathrm{u}}$; (f) $0.85 \mathrm{~N}_{\mathrm{u}}$.

pass through the CFST: one is along the outer wall of the steel tube, and the other is along a straight line through the steel tube wall-concrete-steel tube wall. Since the propagation frequency of ultrasonic waves in concrete is less than that in steel tube, the first and second peaks represent the propagation of ultrasonic waves in concrete and steel tube, respectively. The damage state of concrete can be characterized by the peak amplitude corresponding to the main frequency of concrete. As can be seen from Figures 20 and 21 , when the axial load is 0 , the peak amplitudes corresponding to main frequencies of concrete for YA4-600 and YA5-600 specimens are $272 \mathrm{~dB}$ and $307 \mathrm{~dB}$, respectively. When the axial load is $0.3 \mathrm{Nu}$, these amplitudes are reduced to $234 \mathrm{~dB}$ and $147 \mathrm{~dB}$, respectively. When the axial load is $0.5 \mathrm{Nu}$, they are further reduced to $153 \mathrm{~dB}$ and $127 \mathrm{~dB}$, respectively. However, when the axial load is $0.7 \mathrm{Nu}$, they increase to $246 \mathrm{~dB}$ and $236 \mathrm{~dB}$, respectively. When the axial load is $\mathrm{Nu}$, the peak amplitudes further increase to $263 \mathrm{~dB}$ and $330 \mathrm{~dB}$, respectively. As the axial load continues to increase, the bearing capacity of CFST starts to decrease. When the bearing capacity of CFST decreases to $0.85 \mathrm{Nu}$, the peak amplitudes corresponding to main frequency of concrete for YA4-600 and YA5-600 specimens decrease to $71 \mathrm{~dB}$ and 120, and the CFST specimens are destroyed. The area enclosed by the amplitude of the spectrogram and the abscissa axis represents the energy of the ultrasonic wave. A 
decrease in the area indicates that the energy of the ultrasonic wave is reduced, and the energy dissipation is increased.

\section{Conclusion}

In this study, the axial compression performance of in-line multicavity CFST shear wall was analyzed through a combination of experiment, finite element simulation, and theoretical analysis. The main results of the study are summarized as follows:

(1) The axial compressive tests of the multicavity steel tube with self-compacting concrete shear wall showed that there was no obvious law for local buckling of the steel plate under axial load, and the final failure mode was manifested as multiwave buckling of the steel plate and collapse of the core concrete. During the early stage of loading, the shear wall specimen was in the elastic working stage, and the concrete and steel tube worked independently with almost no synergy. As the axial compression load increased, the shear wall entered the elasticplastic phase. When Poisson's ratio of the steel tube exceeded that of the steel tube, the steel tube generated a tightening force $p$ on the concrete. At this time, the steel tube and concrete were in the $3 \mathrm{D}$ stress state. When the steel tube yielded, the restriction effect of steel tube on the concrete was more significant. With the further expansion of the steel tube to the restraining area of the concrete, such a shear wall exhibited a large load-bearing capacity and good ductility even when its deformation was large.

(2) The established finite element model could well simulate the axial pressure performance of the multicavity steel tube self-compacting concrete-filled shear wall.

(3) Based on parametric analysis, a formula for calculating the bearing capacity of multicavity steel tube self-compacting concrete-filled shear wall was proposed, and the corresponding results were in good agreement with the FEA and test results. This indicates that the proposed formula can serve as a reliable reference for the design of axial compression members of in-line multicavity CFST shear walls.

(4) The mechanical mechanism of multicavity CFST shear wall was analyzed, which revealed that its axial compression mechanism was similar to that of a rectangular steel tube, but the concrete on both sides of the multicavity steel tube was also constrained by the steel tube due to the presence of inner separator. The stress level was maximum at the corner point in the multicavity CFST shear wall, where the longitudinal stress was nearly $66 \mathrm{MPa}$. The stress level was minimum ( 25 MPa) in the middle of the web.

(5) Ultrasonic waves could be effectively used to detect the damage state of concrete in steel tube under axial loading. The ultrasonic frequency spectrograms intuitively reflected the ferrule effect of steel tube as well as the cracking and failure state of core concrete.

(6) The ultrasonic testing results revealed that the damage state of CFST under axial load changed in three characteristic stages. When the axial load was nearly $0.7 \mathrm{Nu}$, the steel tube began to exert restraint on the core concrete.

\section{Data Availability}

The datasets generated and analyzed during the current study are available from the corresponding author upon reasonable request.

\section{Disclosure}

Hongbo Li and Pengfei Yan are the co-first authors.

\section{Conflicts of Interest}

The authors declare no conflicts of interest.

\section{Authors' Contributions}

H. L. and P. Y. incepted the original idea and designed the experiment. H. S. analyzed the data. J. Y. wrote the paper. Hongbo Li and Pengfei Yan contributed equally to this work.

\section{Acknowledgments}

This research was funded by General Project of Research and Development Plan in Ningxia Hui Autonomous Region (2020BDE03005), the Funding Project of First-Class Discipline Construction of University in Ningxia (Domestic First-Class Discipline Construction) under Grant NXYLXK2017A03, the "Yangtze River Scholars and Innovation Team Development Program" Innovation Team of the Ministry of Education (IRT1067), and National Natural Science Foundation of China (52069025).

\section{References}

[1] Y. Bai and G. Shaoyu, "Unified strength theory for concrete filled steel tube columns," Gong Cheng Li Xue/Engineering Mechanics, vol. 36, no. 1, pp. 170-183, 2019.

[2] M. Labibzadeh and R. Hamidi, "A design formula for lateral load resistance of concrete filled double-steel-plate walls with small height-to-length ratio," Ksce Journal of Civil Engineering, vol. 23, no. 4, 2019.

[3] M. Z. M. Raizamzamani, A. R. Azerai, and A. H. Hanizah, "Confinement effects on circular steel tubes filled with foamed concrete (FCFST) subjected to axial thrust and bending," Asian Journal of Civil Engineering, vol. 20, no. 7, pp. 10211035, 2019.

[4] H. Li, H. Sun, W. Zhang, H. Gou, and Q. Yang, "Study on mechanical properties of self-compacting concrete and its filled in-line multi-cavity steel tube bundle shear wall," Energies, vol. 12, no. 18, p. 3466, 2019.

[5] A. K. H. Kwan, C. X. Dong, and J. C. M. Ho, "Axial and lateral stress-strain model for circular concrete-filled steel tubes with external steel confinement," Engineering Structures, vol. 117, no. 15, pp. 528-541, 2016. 
[6] W. L. Cao, H. P. Wu, and J. L. Zhou, "Review on seismic technology progress of steel-concrete composite mega frame column," Journal of Harbin Institute of Technology, vol. 51, no. 12, pp. 1-12, 2019.

[7] F.-x. Ding, L. Fu, and Z.-w. Yu, "Behaviors of axially loaded square concrete-filled steel tube (CFST) Stub columns with notch in steel tube," Thin-Walled Structures, vol. 115, pp. 196-204, 2017.

[8] Y. Liu and B. Young, "Buckling of stainless steel square hollow section compression members," Journal of Constructional Steel Research, vol. 59, no. 2, pp. 165-177, 2003.

[9] X. Chang, L. Fu, H.-B. Zhao, and Y.-B. Zhang, "Behaviors of axially loaded circular concrete-filled steel tube (CFT) stub columns with notch in steel tubes," Thin-Walled Structures, vol. 73, no. 4, pp. 273-280, 2013.

[10] J. Starnes, James, and C. Rose, "American Institute of Aeronautics and Astronautics 38th Structures, Structural Dynamics, and Materials Conference-Kissimmee, FL, USA. (07 April 1997-10 April 1997)," in Proceedings of the 38th Structures, Structural Dynamics, and Materials Conference nonlinear response of thin cylindrical shells with longitudinal cracks and subjected to internal pressure and axial compression loads, Kissimmee, FL, USA, April 1997.

[11] B. C. Chen, Study on construction of concrete-filled steel tube arch bridge, Bridge Construction, no. 3, pp. 55-59, 2002.

[12] Y. J. Liu, L. Jiang, and N. Zhang, "Longitudinal allowable stress of steel tube in concrete-filled steel tube," Journal of Architecture \& Civil Engineering, vol. 32, no. 6, pp. 1-7, 2015.

[13] X. D. Fang, B. Jiang, W. Hong et al., "Axial compressive test and study on steel tube confined high strength concrete shear wall," Journal of Building Structures, vol. 34, no. 3, pp. 100109, 2013.

[14] X. D. Fang, H. Wei, and F. H. Li, "Study on axial bearing capacity of shear wall with steel tube confined high-strength concrete," Journal of Building Structures, vol. 37, no. 8, pp. 11-22, 2016.

[15] X. D. Fang, Q. Li, H. Wei et al., "Experimental study on axialflexural behavior of shear walls with steel tube-confined high performance concrete," Journal of Building Structures, vol. 34, no. 8, pp. 72-81, 2013.

[16] X. D. Fang, H. Wei, and Z. Q. Yao, "Experimental research on tension behavior of shear wall with steel tube-confined highstrength concrete," Journal of Building Structures, vol. 37, no. 5, pp. 1-11, 2016.

[17] X. D. Fang, H. Wei, and Z. Q. Yao, "Experimental research on tensile-shear behaviors of shear wall with steel tube-confined high-strength concrete," Journal of Building Structures, vol. 38, no. 3, pp. 93-102, 2017.

[18] X. D. Fang, H. Wei, and Q. H. Liu, "Experimental study on seismic behavior of shear walls with steel tube-confined high strength concrete," Journal of Building Structures, vol. 36, no. 9, pp. 1-8, 2015.

[19] K. M. A. Hossain, L. K. Mol, and M. S. Anwar, "Axial load behaviour of pierced profiled composite walls with strength enhancement devices," Journal of Constructional Steel Research, vol. 110, pp. 48-64, 2015.

[20] K. M. A. Hossain, S. Rafiei, M. Lachemi, and K. Behdinan, "Structural performance of profiled composite wall under inplane cyclic loading," Engineering Structures, vol. 110, pp. 88-104, 2016.

[21] S. Rafiei, K. M. A. Hossain, M. Lachemi, K. Behdinan, and M. S. Anwar, "Finite element modeling of double skin profiled composite shear wall system under in-plane loadings," Engineering Structures, vol. 56, pp. 46-57, 2013.
[22] S. Rafiei, K. M. A. Hossain, M. Lachemi, and K. Behdinan, "Profiled sandwich composite wall with high performance concrete subjected to monotonic shear," Journal of Constructional Steel Research, vol. 107, pp. 124-136, 2015.

[23] K. Zhang, K. P. Sun, Z. M. Liu et al., "Mechanism of cracks in steel plate-concrete composite shear wall and control measures," Construction Technology, vol. 77, no. 5, pp. 555-556, 2013.

[24] X. Ma, J. Nie, and M. Tao, "Effective stiffness of steel plateconcrete composite shear wall structures in serviceability state," China Civil Engineering Journal, vol. 47, no. 7, pp. 18-26, 2014.

[25] C. J. Gan, X. L. Lv, and W. Wang, "Study on seismic behavior of steel plate reinforced concrete shear walls," Journal of Building Structures, vol. 30, no. 5, pp. 89-96, 2009.

[26] W. J. Zhang, W. L. Cao, and H. Y. Dong, "Performance of cowork between steel plate with studs and outer reinforced concrete in shear wall," Journal of Beijing University of Technology, vol. 38, no. 6, pp. 828-834, 2012.

[27] B. Li, K. N. Luo, and C. Y. Gao, "Study on the mechanical behavior of a multi cavity square concrete filled steel tubular short column under axial compression," Concrete, vol. 4, pp. 37-40+48, 2019.

[28] L. Wang, X. Li, and J. L. Ma, "Study on bending performance of multi-partition steel-concrete composite shear wall," Journal of Guangxi University (Natural Science Edition), vol. 44, no. 3, pp. 747-755, 2019.

[29] Z. Wang, X. Zhou, F. Wei, and M. Li, "Performance of specialshaped concrete-filled square steel tube column under axial compression," Advances in Civil Engineering, vol. 2020, Article ID 1763142, 16 pages, 2020.

[30] J. Liu, Z. Li, and F. X. Ding, "Experimental investigation on the axially loaded performance of notched hexagonal concrete-filled steel tube (CFST) column," Advances in Civil Engineering, vol. 2019, Article ID 2612536, 9 pages, 2019.

[31] F. Yin, S. Z. Xue, and W. L. Cao, "Experimental study on seismic behavior of specially-shaped multi-cell concrete-filled steel tubular columns loaded along different directions," Journal of Building Structures, vol. 40, no. 11, pp. 150-161, 2019.

[32] F. Yin, S. Z. Xue, and W. L. Cao, "Hysteretic behavior of special-shaped multi-cell concrete-filled steel tube under reciprocating axial compression," Journal of Harbin Institute of Technology, vol. 51, no. 12, pp. 94-103, 2019.

[33] M. Chen, X. Z. Chen, and G. Y. Chen, "Ultrasonic wave testing on damage condition of concrete filled steel tube under axial loading," Journal of Northeastern University (Natural Science), vol. 39, no. 10, pp. 93-97, 2018.

[34] M. Chen, Y. M. Jia, and G. Y. Chen, "Research on the damage condition of reinforceed concrete filled steel tubes under axial load using ultrasonic testing," Engineering Mechanics, vol. 36, no. 10, pp. 181-188, 2019.

[35] J. F. Dong, Y. N. Wang, and S. Zan, "Research on ultrasonic detection and treatment about void defects of full-scale concrete filled circular steel tube," Industrial Construction, vol. 47, no. 7, pp. 166-169, 2017.

[36] J. F. Dong, Y. N. Wang, and S. Zan, "Study on ultrasonic detection about void defects of concrete filled rectangular steel tube," Building Science, vol. 34, no. 1, pp. 103-107, 2018.

[37] H. Li, H. Sun, J. Tian, Q. Yang, and Q. Wan, "Mechanical and Ultrasonic Testing of Self-Compacting Concrete," Energies, vol. 12, 2019.

[38] G. L. Golewski, "The influence of microcrack width on the mechanical parameters in concrete with the addition of fly 
ash: consideration of technological and ecological benefits," Construction and Building Materials, vol. 197, pp. 849-861, 2019.

[39] G. L. Golewski, "Energy savings associated with the use of fly ash and nanoadditives in the cement composition," Energies, vol. 13, 2020.

[40] F. Ding, L. Fu, Y. Gong, and Z. Yu, "Behavior of concretefilled square steel tubular stub columns under axially compressive loading," Journal of Shenzhen University Science and Engineering, vol. 31, no. 6, pp. 583-592, 2014.

[41] F.-x. Ding, Z.-w. Yu, Y. Bai, and Y.-z. Gong, "Elasto-plastic analysis of circular concrete-filled steel tube stub columns," Journal of Constructional Steel Research, vol. 67, no. 10, pp. 1567-1577, 2011. 